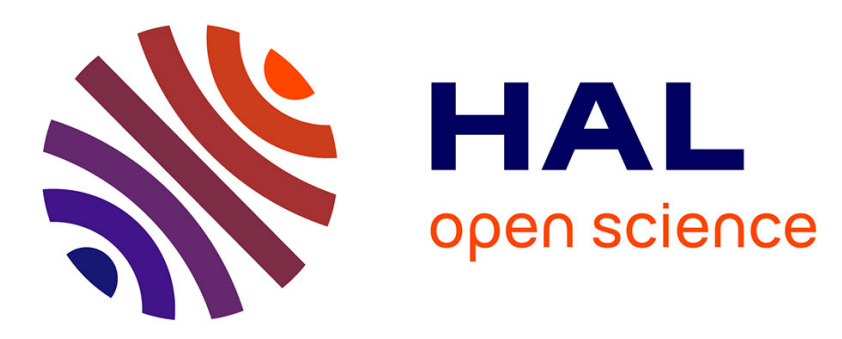

\title{
Anti-ischemic properties of a new spiro-cyclic benzopyran activator of the cardiac mitoK channel
}

Vincenzo Calderone, Lara Testai, Alma Martelli, Simona Rapposelli, Maria

Digiacomo, Aldo Balsamo, Maria C. Breschi

\section{To cite this version:}

Vincenzo Calderone, Lara Testai, Alma Martelli, Simona Rapposelli, Maria Digiacomo, et al.. Antiischemic properties of a new spiro-cyclic benzopyran activator of the cardiac mitoK channel. Biochemical Pharmacology, 2009, 79 (1), pp.39. 10.1016/j.bcp.2009.07.017 . hal-00529098

\section{HAL Id: hal-00529098 \\ https://hal.science/hal-00529098}

Submitted on 25 Oct 2010

HAL is a multi-disciplinary open access archive for the deposit and dissemination of scientific research documents, whether they are published or not. The documents may come from teaching and research institutions in France or abroad, or from public or private research centers.
L'archive ouverte pluridisciplinaire HAL, est destinée au dépôt et à la diffusion de documents scientifiques de niveau recherche, publiés ou non, émanant des établissements d'enseignement et de recherche français ou étrangers, des laboratoires publics ou privés. 


\section{Accepted Manuscript}

Title: Anti-ischemic properties of a new spiro-cyclic benzopyran activator of the cardiac mitoK $_{A T P}$ channel

Authors: Vincenzo Calderone, Lara Testai, Alma Martelli, Simona Rapposelli, Maria Digiacomo, Aldo Balsamo, Maria C. Breschi

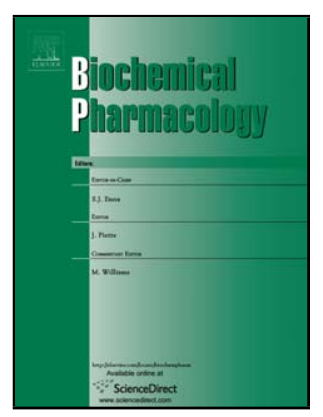

PII: S0006-2952(09)00666-2

DOI: doi:10.1016/j.bcp.2009.07.017

Reference: BCP 10272

To appear in: $\quad B C P$

Received date: $\quad$ 12-6-2009

Revised date: $\quad 14-7-2009$

Accepted date: $\quad$ 27-7-2009

Please cite this article as: Calderone V, Testai L, Martelli A, Rapposelli S, Digiacomo M, Balsamo A, Breschi MC, Anti-ischemic properties of a new spiro-cyclic benzopyran activator of the cardiac mitoK ${ }_{A T P}$ channel, Biochemical Pharmacology (2008), doi:10.1016/j.bcp.2009.07.017

This is a PDF file of an unedited manuscript that has been accepted for publication. As a service to our customers we are providing this early version of the manuscript. The manuscript will undergo copyediting, typesetting, and review of the resulting proof before it is published in its final form. Please note that during the production process errors may be discovered which could affect the content, and all legal disclaimers that apply to the journal pertain. 
Anti-ischemic properties of a new spiro-cyclic benzopyran activator of the cardiac mitoK $\mathrm{ATP}_{\text {channel }}$ Vincenzo Calderone* ${ }^{* 1}$, Lara Testai ${ }^{1}$, Alma Martelli $^{1}$, Simona Rapposelli ${ }^{2}$, Maria Digiacomo ${ }^{2}$, Aldo Balsamo ${ }^{2}$, Maria C. Breschi ${ }^{1}$

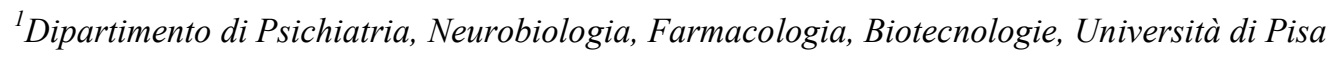

${ }^{2}$ Dipartimento di Scienze Farmaceutiche, Università di Pisa

Graphical abstract

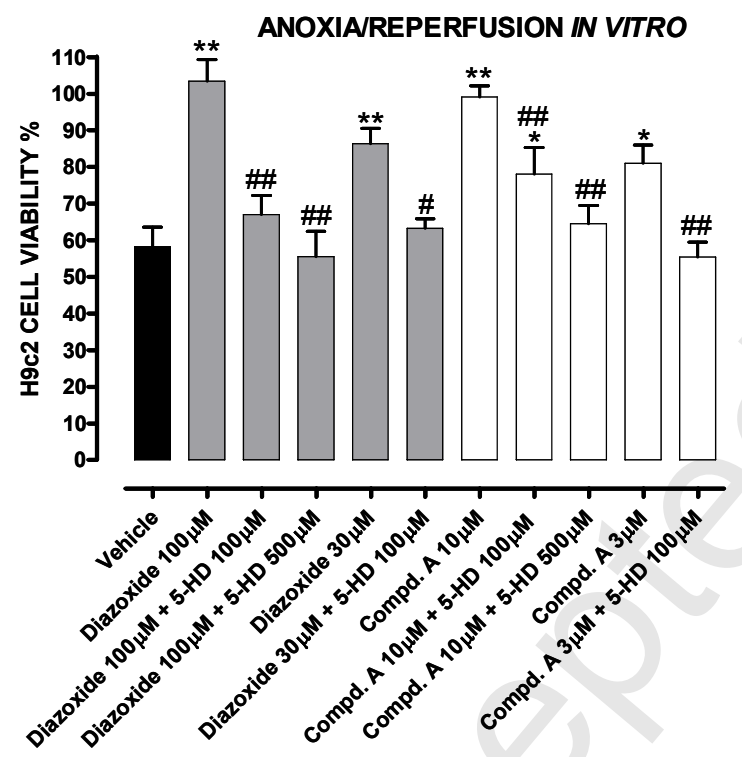<smiles>CC(=O)Nc1ccc(CN2CC3(CC(C)(C)Oc4ccccc43)OCC2=O)cc1</smiles>

Compound A

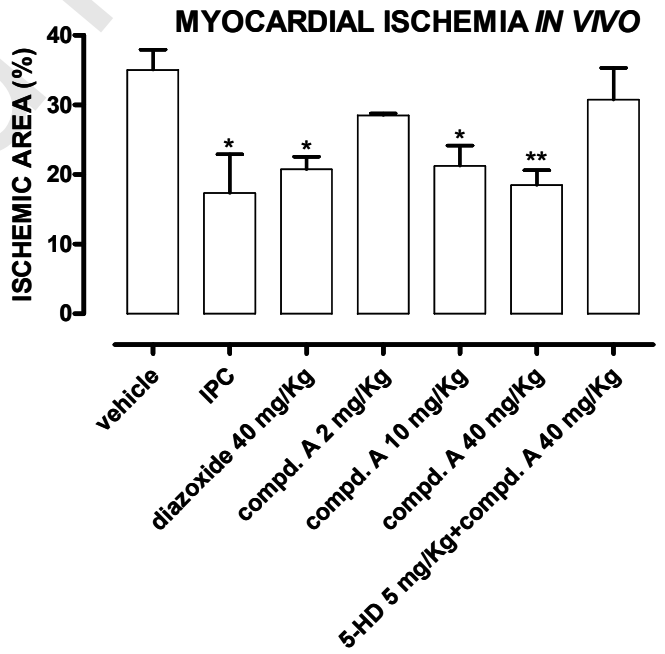




\title{
Anti-ischemic properties of a new spiro-cyclic benzopyran activator of the cardiac mitoK $\mathrm{ATP}_{\mathrm{A}}$ channel
}

\author{
Vincenzo Calderone ${ }^{* 1}$, Lara Testai ${ }^{1}$, Alma Martelli ${ }^{1}$, Simona Rapposelli ${ }^{2}$, \\ Maria Digiacomo $^{2}$, Aldo Balsamo ${ }^{2}$, Maria C. Breschi ${ }^{1}$ \\ ${ }^{1}$ Dipartimento di Psichiatria, Neurobiologia, Farmacologia, Biotecnologie, Università di Pisa \\ ${ }^{2}$ Dipartimento di Scienze Farmaceutiche, Università di Pisa
}

Category: Cardiovascular Pharmacology

*Corresponding author:

Dr. Vincenzo Calderone

Dipartimento di Psichiatria, Neurobiologia, Farmacologia e Biotecnologie, Farmacologia e Biotecnologie, Università di Pisa

Via Bonanno, 6, I-56126 - Pisa, Italy

phone, +39-050-2219589; fax, +39-050-2219609;

E-mail, calderone@,farm.unipi.it.

\begin{abstract}
Abbreviations:
CsA, cyclosporine A; 5-HD, 5-hydroxydecanoic acid; IPC, ischemic pre-conditioning; I/R, ischemia/reperfusion; LAD, left anterior descending coronary artery; $\mathrm{K}_{\mathrm{ATP}}$, ATP-sensitive potassium channel; MPTP, mitochondrial permeability transition pore.
\end{abstract}




\section{Abstract}

Many activators of $\mathrm{K}_{\mathrm{ATP}}$ channels exhibit cardioprotective effects, mainly mediated by channels expressed on mitochondria (mito- $\mathrm{K}_{\mathrm{ATP}}$ ). Previous results showed anti-ischemic effects of the spirocyclic derivative $\mathbf{A}$, on isolated rat hearts. In this work this molecule was more extensively studied and diazoxide was used as reference mito- $\mathrm{K}_{\mathrm{ATP}}$ opener. The studies were performed on an in vivo rat model of myocardial infarct and on heart-derived H9c2 cells exposed to an anoxic environment. The mechanism of action was further investigated on isolated rat heart mitochondria. In the model of myocardial infarct compound A and diazoxide produced significant cardioprotective effects, antagonised by the selective mito- $\mathrm{K}_{\mathrm{ATP}}$ blocker 5-hydroxydecanoic acid (5-HD). Compound A, like diazoxide, produced modest and non-significant hypotensive responses, while the hyperglycaemic effects of diazoxide were not observed for the new compound. Protective effects of compound A and diazoxide were also recorded in H9c2 cells and again were inhibited by 5-HD. Compound A and diazoxide caused swelling of cardiac mitochondria, in agreement with the profile of mito-K $\mathrm{K}_{\text {ATP }}$ openers. Both compounds evoked concentration-dependent $\mathrm{Ca}^{++}$- release from $\mathrm{Ca}^{++}$pre-loaded mitochondria, prevented mitochondrial $\mathrm{Ca}^{++}$- uptake and caused mitochondrial membrane depolarisation. These effects were antagonised by ATP, the endogenous $\mathrm{K}_{\mathrm{ATP}}$ inhibitor. In conclusion, compound $\mathbf{A}$ exhibits a promising profile of an anti-ischemic agent, with a mechanism likely to be linked to the activation of mito- $\mathrm{K}_{\text {ATP }}$ channels, and, because of its chemical characteristics such as structural rigidity and chirality due to the spiro-cyclic moiety, represents an interesting template for development of analogues further improved in activity and selectivity.

Key-words: myocardial ischemia/reperfusion; anti-ischemic drugs; mitochondrial $\mathrm{K}_{\mathrm{ATP}}$ channel; benzopyran $\mathrm{K}_{\mathrm{ATP}}$ activators; spirocyclic derivatives. 


\section{Introduction}

In 1986, Murry and colleagues described an endogenous mechanism for the survival of cardiac tissue, defined as ischemic preconditioning (IPC), in which brief periods of ischemia protect myocardium from following and more sustained ones [1]. IPC is a multi-factorial phenomenon which requires the interaction of several receptor-dependent and receptor-independent processes. Presently, it is widely accepted that ATP-sensitive potassium channels $\left(\mathrm{K}_{\mathrm{ATP}}\right)$, and in particular those expressed in the mitochondrial inner membrane (mito- $\mathrm{K}_{\mathrm{ATP}}$ ) rather than the sarcoplasmatic ones (sarc-K $\left.\mathrm{K}_{\mathrm{ATP}}\right)$, play a key role in IPC.

Really, it should be reported that some authoritative authors attribute the mitochondrial activity of well-known $\mathrm{K}_{\mathrm{ATP}}$-activators to other mechanisms [2,3]. Nevertheless, many $\mathrm{K}_{\mathrm{ATP}}$-openers, belonging to heterogeneous chemical classes (benzopyrans such as cromakalim; cyanoguanidines such as pinacidil; benzothiadiazines, such as diazoxide; etc), have cardioprotective effects [4], thus the sharing of other common ancillary mechanisms is quite improbable. Moreover, the presence of $\mathrm{K}_{\mathrm{ATP}}$ channels (identical to the mammalian ones) and their involvement in IPC phenomena have been recognised in mitochondria of invertebrate animals, suggesting that the mito- $\mathrm{K}_{\mathrm{ATP}}$ channel is actually an evolutionarily well conserved milestone of self-defence pathways [5].

The activation of mito- $\mathrm{K}_{\mathrm{ATP}}$ allows a net influx of $\mathrm{K}^{+}$ions into the matrix, depolarisation of the inner membrane and reduction of the driving force for $\mathrm{Ca}^{++}$uptake $[6,7]$.

During reperfusion, but not during ischemia [8], high mitochondrial $\mathrm{Ca}^{++}$levels promote the irreversible formation of the membrane permeability transition pore (MPTP), which represents the cause of irreversible injury to the cardiac tissue, through the release of pro-apoptotic proteins, such as cytochrome $\mathrm{c}$ [9]. Therefore, the activation of mito- $\mathrm{K}_{\mathrm{ATP}}$ in the ischemic phase might prevent $\mathrm{Ca}^{++}$accumulation in the matrix, blunting the following irreversible opening of MPTP in the reperfusion phase [10]. The reduced $\mathrm{Ca}^{++}-$accumulation in the matrix can account for cardioprotection [11], but this is not an exhaustive explanation for the effects of mito- $\mathrm{K}_{\mathrm{ATP}}$ openers: 
a reduced production of reactive oxygen species by these drugs has been observed in isolated mitochondria, and attributed to $\mathrm{K}^{+}$influx-induced matrix alkalisation [12], mild uncoupling and/or increased oxidation of fatty acids [13]. The $\mathrm{K}^{+}$influx in the mitochondrial matrix is also accompanied by diffusion of water and uptake of anions, resulting in matrix swelling, which is responsible for the preservation of the low permeability of the outer membrane for nucleotides and for the creation of a favourable gradient for ATP synthesis [6,7].

Generally, $\mathrm{K}_{\mathrm{ATP}}$-openers are non-selective activators that target also the sarc- $\mathrm{K}_{\mathrm{ATP}}$ channels expressed in myocardiocytes, in vascular smooth muscle cells and in pancreatic $\beta$-cells, producing many undesired effects, such as vasodilatation and hyperglycaemia [14,15]. Therefore, the development of selective mito- $\mathrm{K}_{\mathrm{ATP}}$ openers is viewed as a challenging issue to obtain antiischemic drugs devoid of side effects related to affinity versus the other subtypes of the $\mathrm{K}_{\mathrm{ATP}}$ channel. For these purposes, the benzopyran scaffold has been subjected to many structural modifications in order to increase the selectivity for the mito- $\mathrm{K}_{\mathrm{ATP}}$ channels. In particular, BMS 180448 and BMS 191095 have been early reported to possess cardioprotective profiles comparable with cromakalim but devoid of vasodilator activity $[16,17]$.

More recently, our group developed new benzopyran derivatives bearing a spiro-cyclic substituent [18,19]. Some molecules, such as 4'-(N-(4-acetamidobenzyl))- 2,2-dimethyl- 2,3-dihydro- 5'Hspiro[chromene- 4,2'- [1,4] oxazinan]- 5'- one (compound A, Fig.1), showed cardioprotective activity on Langendorff-perfused rat hearts submitted to ischemia-reperfusion (I/R), with modest effects on vascular smooth muscle. The cardioprotection was antagonised by 5-hydroxydecanoic acid (5-HD), which is widely used as a selective mito- $\mathrm{K}_{\mathrm{ATP}}$ inhibitor, but unfortunately can have further effects at the mitochondrial level [20,21]. Furthermore, compound A showed an enantioselectivity of action: its $\boldsymbol{S}$-(-)-enantiomer was responsible for the cardioprotective effect, whereas the $\boldsymbol{R}-(+)$-enantiomer was almost ineffective [22].

In this paper, compound $\mathbf{A}$ has been submitted to a more detailed pharmacological study. Although diazoxide is likely to be endowed with further mechanisms, other than its activity on channels 
$[21,23,24]$, this benzothiadiazine is the most commonly used mito- $\mathrm{K}_{\mathrm{ATP}}$ activator, exhibiting a satisfactory level of selectivity. Therefore, diazoxide was selected as reference drug.

\section{Methods}

Male Wistar rats (250-350 g) were housed and cared for in conformity with the Guidelines of the European Community Council Directive 86/609, adopted by Italian law D.L. 116/92, and with the Guide for the Care and Use of Laboratory Animals (NIH n 85-23, revised 1996). The protocols were approved by the ethical committee of University of Pisa. Compound $\mathbf{A}$ was synthesised and chemically characterised as previously published [18].

\subsection{In vivo model of coronary occlusion-reperfusion}

The experimental protocol for coronary occlusion-reperfusion has been performed as described in [25], with minor modifications. Two hours before the experimental procedures, rats received an i.p. injection of the reference drug diazoxide (40 mg/Kg, Sigma-Aldrich, St. Louis, MO, USA), compound A (2, 10 or $40 \mathrm{mg} / \mathrm{Kg}$ ), or vehicle (dimethylsulphoxide, DMSO, Sigma-Aldrich, St. Louis, MO, USA). When required, the mito-K $\mathrm{K}_{\text {ATP }}$ blocker 5 -HD (5 mg/Kg, Sigma-Aldrich, St. Louis, MO, USA) was injected 20 min before the treatment with the mito- $\mathrm{K}_{\text {ATP }}$ opener. The doses of the tested compounds were selected on the basis of the previous work [18].

Then, rats were anaesthetised with sodium pentobarbital (70 mg/kg, i.p.). The trachea was intubated and connected to a rodent ventilator (mod. 7025 Ugo Basile, Comerio, Italy) for artificial ventilation with room air (stroke volume, $1 \mathrm{ml} / 100 \mathrm{~g}$ body weight; 70 strokes $/ \mathrm{min}$ ). Electrocardiogram (ECG) was continuously measured by lead II (Mindray, PM5000). The chest was opened by a left thoracotomy. A 6-0 surgical needle was passed around the left anterior descending coronary artery (LAD), located between the base of the pulmonary artery and left atrium. The ends of the suture were passed through a polypropylene tube (PE50) to form a snare. To induce infarction, the LAD was occluded by pulling the snare and then fixing it in place by 
clamping the tube with a haemostat, when the snare was released the reperfusion was initiated. The acute infarct protocol consisted of 30' occlusion/120' reperfusion; successful occlusion was confirmed visually by regional cyanosis downstream of the ligature and by ST elevation on the ECG.

A group of vehicle-pretreated animals was submitted to an IPC procedure, achieved by 2 cycles of $5^{\prime}$ occlusion $/ 10^{\prime}$ reperfusion, followed by $30^{\prime}$ coronary occlusion and $120^{\prime}$ reperfusion. Each experimental group was composed of at least 6 animals.

At the end of reperfusion, rats were euthanised by an overdose of pentobarbital sodium, then hearts were quickly excised, mounted on a Langendorff apparatus and perfused for 10' with Krebs solution at $37^{\circ} \mathrm{C}$ to wash out the coronary blood vessels. Then, hearts were deprived of the atria and right ventricle. The left ventricular tissue was dried, frozen, and cut into 4-5 transverse slices from apex to base of equal thickness (about $2 \mathrm{~mm}$ ). The slices were then incubated in a 1\% 2,3,5triphenyltetrazolium chloride (TTC, Sigma-Aldrich, St. Louis, MO, USA) solution in a phosphate buffer (pH 7.4) at $37^{\circ} \mathrm{C}$ for $20 \mathrm{~min}$.

TTC reacts with NADH in the presence of dehydrogenase enzymes, to form a formazan derivative causing the staining of viable cells with intense red colour. Then, the slices were fixed overnight in $10 \%$ formaldehyde and finally they were photographed. Red-stained viable tissue was easily distinguished from the infracted white-unstained necrotic tissue. The infarct area (Ai) was planimetrically evaluated using an image analyser program (The GIMP 2). The infarct size was calculated as a percentage of the whole area of the left ventricle $\left(\mathrm{Ai} / \mathrm{A}_{\mathrm{LV}} \%\right)$.

\subsection{In vivo assessment of systolic blood pressure}

The experimental protocol was performed as already described in [18]. In order to reproduce the same conditions used for the evaluation of the cardioprotective effects, the animals were anaesthetised with sodium pentobarbital $(60 \mathrm{mg} / \mathrm{Kg})$. After the administration of the anaesthetic drug, the animal tails were exposed for 15-20 minutes to irradiation with an I.R. lamp to cause 
vasodilation of the tail-vessels. Then, three basal systolic blood pressure values were sphygmomanometrically recorded with the "tail-cuff" method by a BP recorder (Ugo Basile 58500, Italy) at 5-min intervals. Then, the animals were treated with an i.p. administration of vehicle, diazoxide $40 \mathrm{mg} / \mathrm{Kg}$, compound A $40 \mathrm{mg} / \mathrm{Kg}$ or the potent $\mathrm{K}_{\mathrm{ATP}}$-activator cromakalim $1 \mathrm{mg} / \mathrm{Kg}$, i.e. the dose which exhibited significant anti-ischemic effects in the previous work [18]. The systolic blood pressure values were recorded for 1 hour at intervals of $5 \mathrm{~min}$ (during this period, a maintenance dose of $10 \mathrm{mg} / \mathrm{Kg}$ sodium pentobarbital was administered, when required). Each experimental group was composed of 6 animals.

\subsection{Glucose tolerance}

The experimental protocol has been performed as described in [26], with some modifications. In order to reproduce the same conditions used for the evaluation of the cardioprotective effects, the animals were anaesthetised with sodium pentobarbital $(60 \mathrm{mg} / \mathrm{Kg})$. After the induction of anaesthesia, basal glycaemic levels were monitored by means of the usual glucose-titration kit (New Glucocard G sensor and Glucocard Gmeter, Arkray, A. Menarini diagnostics, Italy). Then, rats were treated with an i.p. injection of vehicle, diazoxide $40 \mathrm{mg} / \mathrm{Kg}$ or compound $\mathbf{A} 40 \mathrm{mg} / \mathrm{Kg}$. Twenty minutes after the pharmacological treatment, glycaemia was measured again and then the rats received an i.p. administration of glucose $1 \mathrm{~g} / \mathrm{Kg}$ and glycaemia was regularly monitored for the following 2 hours. Each experimental group was composed of 6 animals.

\subsection{Cell culture}

H9c2 subclonal cell line derives from embryonic rat hearts [27]; although it exhibits also some characteristics of scheletal muscle cells, it is widely used as a valuable cellular model for studies of myocardial ischemia/reperfusion [25,28,29]. H9c2 cells (ATTC, Manassas, VA, USA) were cultured, following the usual procedures in Dulbecco's modified Eagle's medium (DMEM, SigmaAldrich, St. Louis, MO, USA) supplemented with 10\% fetal bovine serum (FBS, Sigma-Aldrich, St. 
Louis, MO, USA), 100 units $/ \mathrm{ml}$ penicillin and $100 \mu \mathrm{g} / \mathrm{ml}$ streptomycin in tissue culture flasks at $37^{\circ} \mathrm{C}$ in a humidified atmosphere of $5 \% \mathrm{CO}_{2}$.

H9c2 cells were cultured up to about $80 \%$ confluence in a DMEM medium and 24 hours before the experiment, cells were seeded onto 96 -well plates at a density of $8 \times 10^{3}$ per well. After 24 hours to allow cell attachment, the medium was replaced in each 96-well plate and the cells received different treatments such as: vehicle (that is $0.05 \%$ DMSO), diazoxide (30 or $100 \mu \mathrm{M})$, compound $\mathbf{A}$ (3 or $10 \mu \mathrm{M}), 5$-HD $(100$ or $500 \mu \mathrm{M})$ plus diazoxide $(30$ or $100 \mu \mathrm{M}), 5-\mathrm{HD}(100$ or $500 \mu \mathrm{M})$ plus compound A (3 or $10 \mu \mathrm{M})$. The concentrations of diazoxide and 5-HD where selected on the basis of the experimental protocols usually reported in literature [11]. Then, one plate was placed for 16 hours in an airtight AtmosBag (Sigma-Aldrich) which was saturated with $95 \% \mathrm{~N}_{2}$ and $5 \% \mathrm{CO}_{2}$ to simulate ischemia, while the twin plate was placed for 16 hours in an airtight AtmosBag which was saturated with $95 \%$ air and $5 \% \mathrm{CO}_{2}$. At the end of the hypoxia period all the cells were subjected to reperfusion by replacing the medium with DMEM and incubation for 2 hours in an atmosphere containing $5 \% \mathrm{CO}_{2} / 95 \%$ air at $37^{\circ} \mathrm{C}$. After reperfusion, cell viability was assessed using the Cell Proliferation Reagent WST-1 (4-[3-(4-iodophenyl)-2-(4-nitrophenyl)-2H-5-tetrazolium]-1,3benzene disulphonate) (Roche, Mannheim, Germany) based on the cellular cleavage of the WST-1 to formazan. WST-1 was added at $1 / 10$ of the total volume and after $60 \mathrm{~min}$ of incubation at $37^{\circ} \mathrm{C}$, the absorbance was measured at $450 \mathrm{~nm}$ with a microplate reader (Wallac; PerkinElmer, Wellesley, MA, USA). Absorbance values were normalised as a \% of the absorbance shown by vehicle-treated cells exposed in the non-hypoxic atmosphere (Viab. \%). Three different experiments were performed in six replicates.

\subsection{Rat cardiac mitochondria}

\subsubsection{Isolation procedure}

Rat cardiac mitochondria were isolated by differential centrifugation, as described [30], with minor modifications. Male Wistar rats were killed by cervical dislocation, the heart was removed 
immediately and placed in ice cold isolation buffer (composition: sucrose $250 \mathrm{mM}$, Tris $5 \mathrm{mM}$, EGTA $1 \mathrm{mM}$, pH 7.4 adjusted with $\mathrm{HCl}$ ). The atria were removed and the ventricular tissue was finely minced with surgical scissors (about $2 \mathrm{~mm}^{3}$ pieces) and homogenised using an Ultra-Turrax homogeniser (20 $\mathrm{ml}$ of isolation buffer per heart).

Three 20sec homogenisation cycles were performed on ice, and then the suspension was centrifuged at $1075 \mathrm{xg}$ for $3 \mathrm{~min}$ at $4^{\circ} \mathrm{C}$. The resulting supernatant was centrifuged at $11950 \mathrm{xg}$ for $10 \mathrm{~min}$ at $4^{\circ} \mathrm{C}$. The pellet containing the mitochondrial fraction was further re-suspended in the isolation buffer (without EGTA) and centrifuged at $11950 \mathrm{xg}$ for $10 \mathrm{~min}$ at $4^{\circ} \mathrm{C}$, this step was repeated once more.

The final mitochondrial pellet was re-suspended in a minimal volume of $400 \mu$ of the isolation buffer (without EGTA) and stored on ice throughout the experiment, which was performed within 2 hours. Mitochondrial protein concentrations were determined using the Bradford reaction.

Previous experiments (data not shown) confirmed the reliability of the isolation procedures, by measurement of the mitochondrial respiratory function through an ATP bioluminescence assay, in agreement with the method of Drew and Leeuwenburgh [31]. Briefly, mitochondria (1 mg protein $/ \mathrm{ml}$ ) were suspended in the isolation buffer (without EGTA) enriched with succinate $20 \mathrm{mM}$, $\mathrm{KH}_{2} \mathrm{PO}_{4} 30 \mathrm{mM}$ and ADP 5' diphosphate $200 \mu \mathrm{M}$. The reaction was initiated by the addition of a luciferin-luciferase reagent. ADP 5' diphosphate replaced by bidistilled water was used as a blank. 3 min after the start of reaction, the measurement was performed using a luminometer (Wallac, Perkin Elmer, Wellesley, MA, USA). In all the tested preparations, the assay really detected the light produced by the ATP-dependent oxidation of luciferin by means of the luciferase enzyme. The ATP-synthase inhibitor olygomicin $2 \mu \mathrm{g} / \mathrm{ml}$ (Sigma-Aldrich, St. Louis, MO, USA) or the uncoupler of oxidative phosphorylation 2,4-dinitrophenol (100 $\mu \mathrm{M}$, Sigma-Aldrich, St. Louis, MO, USA) inhibited ATP production.

\subsubsection{Mitochondrial swelling}


Mitochondrial swelling was assessed spectrophotometrically [32] by measuring the change in absorbance of the suspension at $520 \mathrm{~nm}$ (Wallac, Perkin Elmer, Wellesley, MA, USA).

Mitochondria $(1 \mathrm{mg}$ protein $/ \mathrm{ml})$ were suspended in an incubation medium under gently stirring (composition: $\mathrm{KCl} 120 \mathrm{mM}, \mathrm{K}_{2} \mathrm{HPO}_{4} 5 \mathrm{mM}$, Hepes $10 \mathrm{mM}$, succinic acid $10 \mathrm{mM}, \mathrm{MgCl}_{2} 2 \mathrm{mM}$, ATP $200 \mu \mathrm{M}$, pH 7.4 adjusted with $\mathrm{KOH})$. The decrease of absorbance was monitored for $15 \mathrm{~min}$ after the addition of $\mathbf{A}(10$ and $100 \mu \mathrm{M})$, diazoxide $(10$ and $100 \mu \mathrm{M})$, or vehicle (DMSO $1 \%)$. Each time-response curve was obtained with mitochondria isolated from the hearts of at least 6 different animals.

\subsubsection{Mitochondrial $\mathrm{Ca}^{++}$- release}

Changes of the medium (i.e. extra-mitochondrial) $\mathrm{Ca}^{++}$concentration were continuously measured with a $\mathrm{Ca}^{++}$selective mini-electrode [30], coupled with a reference electrode (WPI, FL, USA), using a data acquisition software (Biopac Inc. California, USA). The selectivity of the electrode for $\mathrm{Ca}^{++}$over other cations, such as $\mathrm{Mg}^{2+}, \mathrm{K}^{+}$and $\mathrm{Na}^{+}$, was $>10^{5}$. In order to correlate the potentiometric measurements (in $\mathrm{mV}$ ) with the corresponding concentrations of $\mathrm{Ca}^{++}$ions in the solution, opportune calibration curves were generated before each experiment using known concentrations of $\mathrm{CaCl}_{2}$. Mitochondria $(1 \mathrm{mg}$ protein $/ \mathrm{ml})$ were suspended under gently stirring in the incubation medium (composition: $\mathrm{KCl} 120 \mathrm{mM}, \mathrm{K}_{2} \mathrm{HPO}_{4} 5 \mathrm{mM}$, Hepes $10 \mathrm{mM}$, succinic acid $10 \mathrm{mM}, \mathrm{MgCl}_{2} 2 \mathrm{mM}, \mathrm{CaCl}_{2} 100 \mu \mathrm{M}, \mathrm{pH} 7.4$ adjusted with $\left.\mathrm{KOH}\right)$. Mitochondrial $\mathrm{Ca}^{++}$- release was induced 5 min after the rapid $\mathrm{Ca}^{++}$accumulation, by adding, in the incubation medium at 5 min intervals, cumulative increasing concentrations of compound $\mathbf{A}(3-300 \mu \mathrm{M})$ or the reference drug diazoxide (3-300 $\mu \mathrm{M})$. The potassium ionophore valinomycin $(2 \mathrm{nM}-2 \mu \mathrm{M})$ (Sigma-Aldrich, St. Louis, MO, USA), was also used as a reference channel-independent drug causing $\mathrm{K}^{+}$influx in mitochondria. When required, ATP $(200 \mu \mathrm{M})$, used to inhibit the mito- $\mathrm{K}_{\mathrm{ATP}}$ channels, and cyclosporine A (CsA, $0.2 \mu \mathrm{M}$, Sigma-Aldrich, St. Louis, MO, USA), MPTP blocker, were incubated $2 \mathrm{~min}$ before the cumulative addition of the $\mathrm{K}_{\mathrm{ATP}}$ - openers. Each concentration-response curve was obtained with mitochondria isolated from the hearts of at least 6 different animals. 


\subsubsection{Mitochondrial $\mathrm{Ca}^{++}$- uptake}

Mitochondrial $\mathrm{Ca}^{++}$- uptake was potentiometrically measured [30] following the above reported protocol, with the following modification: mitochondria ( $1 \mathrm{mg}$ protein/ml) were added under gently stirring to the incubation medium (composition: $\mathrm{KCl} 120 \mathrm{mM}, \mathrm{K}_{2} \mathrm{HPO}_{4} 5 \mathrm{mM}$, Hepes $10 \mathrm{mM}$, succinic acid $10 \mathrm{mM}, \mathrm{MgCl}_{2} 2 \mathrm{mM}, \mathrm{CaCl}_{2} 100 \mu \mathrm{M}, \mathrm{pH} 7.4$ adjusted with $\mathrm{KOH}$ ), medicated with vehicle (DMSO 1\%), diazoxide $(100 \mathrm{mM})$ or compound A $(300 \mathrm{mM})$. The maximal variation of concentration of $\mathrm{Ca}^{++}$in the medium, related to its accumulation in the mitochondrial matrix, was measured. Each result was obtained with mitochondria isolated from the hearts of at least 3 different animals.

\subsubsection{Mitochondrial membrane potential}

Mitochondrial membrane potential $(\Delta \psi)$ was potentiometrically measured with tetraphenylphosphonium $\left(\mathrm{TPP}^{+}\right)$-sensitive mini-electrodes [33], coupled with a reference electrode (WPI, FL, USA), using a data acquisition software (Biopac Inc. California, USA). Electrodes were calibrated before each experiment using known concentrations of $\mathrm{TPP}^{+} \mathrm{Cl}^{-}$(Sigma-Aldrich). Mitochondria (2 mg protein $/ \mathrm{ml}$ ) were suspended under gently stirring in the incubation medium (composition: $\mathrm{KCl} 120 \mathrm{mM}, \mathrm{K}_{2} \mathrm{HPO}_{4} 5 \mathrm{mM}$, Hepes $10 \mathrm{mM}$, succinic acid $10 \mathrm{mM}, \mathrm{MgCl}_{2} 2 \mathrm{mM}$, EGTA $1 \mathrm{mM}, \mathrm{pH} 7.4$ adjusted with $\mathrm{KOH}$ ). The value of the potential was calculated according to the following Nernst-derived experimental equation:

$$
\Delta \psi=60 \times \log \frac{V_{0} \cdot \frac{\left[T P P^{+}\right]_{0}}{\left[T P P^{+}\right]_{t}}-V_{t}-K_{0} P}{V_{m} P+K_{i} P}
$$

Where $\Delta \psi$ is the mitochondrial membrane potential $(\mathrm{mV}), \mathrm{V}_{0}$ is the volume of the incubation medium before the mitochondria addition, $V_{t}$ is the volume of the incubation medium after the mitochondria addition, $\mathrm{V}_{\mathrm{m}}$ is the volume of mitochondrial matrix ( $\mu \mathrm{l} / \mathrm{mg}$ protein), $\left[\mathrm{TPP}^{+}\right]_{0}$ and $\left[\mathrm{TPP}^{+}\right]_{\mathrm{t}}$ are concentrations of $\mathrm{TPP}^{+}$before the addition of mitochondria and at time $\mathrm{t}$, respectively, $\mathrm{P}$ 
is the protein concentration $(\mathrm{mg}), \mathrm{K}_{0}$ and $\mathrm{Ki}$ are apparent external and internal partition coefficients of $\mathrm{TPP}^{+}$, and were estimated as $14.3 \mu \mathrm{l} / \mathrm{mg}$ and $7.9 \mu \mathrm{l} / \mathrm{mg}$, respectively. The volume of mitochondria was taken as $1 \mu \mathrm{l} / \mathrm{mg}$ of protein [33].

Changes of $\Delta \psi$ were continuously recorded before and after the addition in the incubation medium of cumulative increasing concentrations of compound $\mathbf{A}(10-300 \mu \mathrm{M})$ or the reference drug diazoxide $(10-300 \mu \mathrm{M})$.

The potassium ionophore valinomycin $2 \mathrm{nM}-2 \mu \mathrm{M}$ (Sigma-Aldrich) was also used as a reference channel-independent drug causing $\mathrm{K}^{+}$influx in mitochondria. When required, ATP $(200 \mu \mathrm{M})$, used to inhibit the mito-K $\mathrm{K}_{\mathrm{ATP}}$ channels, was incubated in the medium, $2 \mathrm{~min}$ before the mitochondria addition. Each concentration-response curve was obtained with mitochondria isolated from the hearts of at least 6 different animals.

\subsection{Data analysis}

All data are expressed as mean \pm standard error. Concentration response curves were analysed by a non-linear fitting equation by computerised methods (software: GraphPadPrism 4.0). Data were statistically analysed by ANOVA and P values lower than 0.05 were considered as indicative of significant differences.

\section{Results}

\subsection{Acute infarct}

Hearts of vehicle-treated animals submitted to LAD ligature showed clear evidence of I/R injury, with a large amount of damaged tissue $\left(\mathrm{Ai} / \mathrm{A}_{\mathrm{LV}}=35 \pm 3 \%\right)$. As expected, preconditioning protocol afforded significant cardioprotective effects, producing about a half-reduction of the damaged areas $\left(\mathrm{Ai} / \mathrm{A}_{\mathrm{LV}}=17 \pm 6 \%\right)$ and pre-treatment with diazoxide $(40 \mathrm{mg} / \mathrm{Kg})$ led to almost equivalent antiischemic effects $\left(\mathrm{Ai} / \mathrm{A}_{\mathrm{LV}}=21 \pm 2 \%\right)$. 
Pharmacological treatment with increasing doses $(2,10,40 \mathrm{mg} / \mathrm{Kg})$ of compound $\mathbf{A}$, produced significant and dose-dependent cardioprotective responses $\left(\mathrm{Ai} / \mathrm{A}_{\mathrm{LV}}=29 \pm 1 \%, 21 \pm 3 \%\right.$ and $18 \pm 2 \%$ respectively). When tested on 5-HD (5 mg/Kg) pre-treated animals, compound $\mathbf{A}(40 \mathrm{mg} / \mathrm{Kg})$ failed to exhibit any significant cardioprotective activity (Fig. 2). 5-HD (5 mg/Kg) fully antagonised also the effects of diazoxide (data not shown).

\subsection{Blood pressure}

The administration of diazoxide and compound A (both at the dose of $40 \mathrm{mg} / \mathrm{Kg}$ i.p.) was followed by a weak and not significant decrease of systolic blood pressure, with a maximal decrease of about $15 \%$ and without any significant alteration of heart rate (Fig. 3). Cromakalim, a well-known $\mathrm{K}_{\text {ATP }^{-}}$ activator endowed with heavy hypotensive effects, was also selected for this protocol and administered at the dose of $1 \mathrm{mg} / \mathrm{Kg}$ i.p., which exhibited anti-ischemic effects in the previous study [18]. Cromakalim caused an immediate dramatic and long-lasting decrease (about 50\%) of systolic blood pressure, which was associated with a significant compensatory tachycardia (Fig. 3).

\subsection{Glucose metabolism}

The administration of diazoxide (40 mg/Kg i.p.) determined per se an appreciable (but not statistically significant) increase (about $40 \%$ ) of non-fasting glycaemic levels; moreover, in the i.p. glucose tolerance test, this benzothiadiazine caused an higher glycaemic peak and delayed the recovery of normoglycaemic levels. Compound A was completely devoid of effects on glucose metabolism (Fig. 4).

\subsection{H9c2 cell viability}

The incubation in an anoxic environment $\left(95 \% \mathrm{~N}_{2}\right.$ and $\left.5 \% \mathrm{CO}_{2}\right)$ caused a drastic reduction of $\mathrm{H} 9 \mathrm{c} 2$ cell viability $($ Viab. $\%=58 \pm 5)$. Pre-treatment of cells with diazoxide $(100 \mu \mathrm{M})$ and $\mathbf{A}(10 \mu \mathrm{M})$ conferred a strong resistance, producing a full preservation of cell viability (Viab. $\%=103 \pm 6$ and 
$99 \pm 3$, respectively). 5-HD (100 and $500 \mu \mathrm{M})$ fully antagonised the protective effects of diazoxide $100 \mu \mathrm{M}($ Viab. $\%=67 \pm 5$ and $55 \pm 7$, respectively). The protective activity of compound $\mathrm{A} 10 \mu \mathrm{M}$

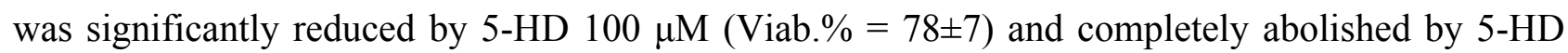
$500 \mu \mathrm{M}($ Viab. $\%=64 \pm 5)$.

Lower concentrations of diazoxide $(30 \mu \mathrm{M})$ and $\mathbf{A}(3 \mu \mathrm{M})$ still conferred appreciable levels of resistance, causing a significant preservation of cell viability (Viab.\% $=86 \pm 4$ and $81 \pm 5$, respectively). The effects of both diazoxide and compound A were almost completely abolished by 5-HD $100 \mu \mathrm{M}$ (Viab.\% = 63 \pm 3 and 55 \pm , respectively) (Fig. 5). Preliminary experiments showed that 5-HD alone (100 and $500 \mu \mathrm{M})$ does not influence the cell viability.

\subsection{Mitochondrial swelling}

The spectrophotometrical evaluation of the influence of the test compounds on the matrix volume showed that both diazoxide and compound $\mathbf{A}$ evoked mitochondrial swelling. In particular, the decreases in absorbance at $520 \mathrm{~nm}$ recorded $15 \mathrm{~min}$ after the addition of diazoxide $100 \mu \mathrm{M}$ or compound A $100 \mu \mathrm{M}$ were $0.110 \pm 0.013$ and $0.123 \pm 0.014$ (in absorbance arbitrary units), respectively (Fig. 6). Compound $\mathbf{A}$ and diazoxide, both tested at $10 \mu \mathrm{M}$, did not produce any significant decrease of absorbance (Fig. 6).

\section{6 $\mathrm{Ca}^{++}$- release from pre-loaded mitochondria}

$\mathrm{Ca}^{++}$ions $(100 \mu \mathrm{M})$ were rapidly and almost fully accumulated by mitochondria. The $\mathrm{K}^{+}$-ionophore valinomycin $(2 \mathrm{nM}-2 \mu \mathrm{M})$ caused a concentration-dependent massive $\mathrm{Ca}^{++}$- release from $\mathrm{Ca}^{++}$preloaded mitochondria; an almost complete release of the ion was induced by valinomycin $20 \mathrm{nM}$ (data not shown).

Diazoxide (10-300 $\mu \mathrm{M})$ and compound $\mathbf{A}(10-300 \mu \mathrm{M})$ induced a concentration-dependent outflow of $\mathrm{Ca}^{++}$, and the former exhibited a level of potency $\left(\mathrm{pEC}_{50}=4.78 \pm 0.12\right)$ about one order of 
magnitude higher than the latter $\left(\mathrm{pEC}_{50}=3.89 \pm 0.04\right)$. The effects of diazoxide and compound $\mathbf{A}$ were strongly antagonised by both ATP $200 \mu \mathrm{M}$ and CsA $0.2 \mu \mathrm{M}$ (Fig. 7).

\section{7 $\mathrm{Ca}^{++}$- uptake into $\mathrm{Ca}^{++}$- free mitochondria}

The addition of $\mathrm{Ca}^{++}$- free mitochondria to the $\mathrm{Ca}^{++}$- rich medium medicated with the vehicle led to a rapid and dramatic decrease of the ion concentration in the medium, corresponding to an efficient accumulation of the cation in the mitochondrial matrix. The final concentration of $\mathrm{Ca}^{++}$was stably reached within 1-2 min and was $8 \pm 3 \mu \mathrm{M}$.

The addition of $\mathrm{Ca}^{++}$- free mitochondria to the $\mathrm{Ca}^{++}$- rich medium medicated with diazoxide 100 $\mu \mathrm{M}$ (i.e., the concentration evoking an almost maximal effect on $\mathrm{Ca}^{++}$-release from $\mathrm{Ca}^{++}$preoaded mitochondria) led to a very modest decrease of the ion concentration in the medium, corresponding to significant abolition of the process of accumulation of the cation in the mitochondrial matrix. The final concentration of $\mathrm{Ca}^{++}$was stably reached within 1-2 min and was $88 \pm 6 \mu \mathrm{M}$.

As observed for diazoxide, the addition of $\mathrm{Ca}^{++}$- free mitochondria to the $\mathrm{Ca}^{++}$- rich medium medicated with compound A $300 \mu \mathrm{M}$ (i.e., the concentration evoking an almost maximal effect on $\mathrm{Ca}^{++}$-release from $\mathrm{Ca}^{++}$preoaded mitochondria) led to a very modest decrease of the ion concentration in the medium, corresponding to significant inhibition of the process of upload of the cation in the mitochondrial matrix. The final concentration of $\mathrm{Ca}^{++}$was stably reached within 1-2 min and was $79 \pm 7 \mu \mathrm{M}$ (Fig. 8).

\subsection{Mitochondrial membrane potential}

Isolated heart mitochondria showed basal levels of $\Delta \psi$ ranging around $-180 \mathrm{mV}$. Both diazoxide $(10-300 \mu \mathrm{M})$ and compound $\mathbf{A}(10-300 \mu \mathrm{M})$ determined a partial depolarisation of mitochondria, with maximal effects of about $25 \mathrm{mV}$. In particular, significant effects of diazoxide started at relatively low concentrations (starting from $30 \mu \mathrm{M}$ ) and proceeded in a more evident concentration- 
dependent fashion. As already observed in the experiments on mitochondrial $\mathrm{Ca}^{++}$- release, compound A evoked a marked and significant depolarising response only at the highest concentration of $300 \mu \mathrm{M}$. ATP $200 \mathrm{mM}$ antagonised the effects of both derivatives (Fig. 9). Valinomycin showed powerful effects (with maximal depolarisation of about $60 \mathrm{mV}$, produced by valinimycin $20 \mathrm{nM}$ ), which were not influenced by ATP (data not shown). Moreover, the relationships between changes in membrane potential and $\mathrm{Ca}^{++}$-release from the matrix were further examined. In particular, each concentration of the tested drugs (both diazoxide and compound $\mathbf{A}$ ) produced on isolated mitochondria a couple of data: a value of $\Delta \psi$ modification and a value of $\mathrm{Ca}^{++}$-release. All these couples of experimental values have been reciprocally plotted (Fig. 10) and the linear regression analysis clearly confirmed that the two effects are closely correlated $(\mathrm{R} 2=$ $0.95)$.

\section{Discussion}

In this study, compound $\mathbf{A}$ was tested in an experimental model of acute infarct, more closely resembling the complex clinical pattern of the heart infarct. The in vivo study also addressed the evaluation of the potential impact of the new molecule on blood pressure and glucose metabolism, which are typical undesired effects of non-selective agents, clearly due to the activation of sarc$\mathrm{K}_{\mathrm{ATP}}$ channels expressed in vascular smooth muscle and pancreatic beta cells.

In the model of experimentally-induced infarct, compound $\mathbf{A}$ showed cardioprotective effects almost comparable to that produced by the exogenous "self-defence" mechanism of IPC. Moreover, the anti-ischemic effects of compound $\mathbf{A}$ showed a dose-dependent fashion and were equivalent (or slightly superior) to those of the reference drug diazoxide. As already observed in the previous studies on isolated hearts, the cardioprotective effects of compound $\mathbf{A}$ were inhibited by 5 -HD, a putative selective blocker of mito- $\mathrm{K}_{\mathrm{ATP}}$ channels.

Both compound $\mathbf{A}$ and diazoxide (tested at the dose of $40 \mathrm{mg} / \mathrm{Kg}$ i.p., that induced clear and significant cardioprotection) caused modest and not significant alterations of systolic blood pressure 
and heart rate, while the potent and non-selective $\mathrm{K}_{\mathrm{ATP}}$-opener cromakalim (at the i.p. dose of 1 $\mathrm{mg} / \mathrm{Kg}$, i.e. the one which induced significant cardioprotection in the previous work) caused an immediate and dramatic fall of the arterial pressure, associated with a compensatory tachycardic response. As regards the impact on glucose metabolism, in good agreement with other experimental observations [34], diazoxide caused a marked (about 40\%), albeit not significant, increase of the basal levels of non-fasting glycaemia. Furthermore, the test of intraperitoneal glucose tolerance demonstrated a strong and significant hyperglycaemic response in diazoxide-treated rats. Compound A was completely ineffective on glucose metabolism, indicating that this spiro-cyclic derivative, at the dose inducing cardioprotective effects, is unlikely to interact significantly with potassium channels of pancreatic beta cells.

The probable involvement of mito- $\mathrm{K}_{\mathrm{ATP}}$ channels emerged also from the experimental protocols on cultured $\mathrm{H} 9 \mathrm{c} 2$ cells. In these cells, the anoxic condition caused a dramatic impact, leading to a high level of cell death. Both diazoxide and compound A (at concentrations about one order of magnitude lower than the reference benzothiadiazine) produced powerful protective effects against the cell injury induced by the incubation of $\mathrm{H} 9 \mathrm{c} 2$ cultures in the anoxic atmosphere. Again, the mito- $\mathrm{K}_{\mathrm{ATP}}$ blocker 5-HD antagonised the protective effects.

Therefore, the studies were focused on the identification of characteristic effects of compound $\mathbf{A}$ at the mitochondrial level.

Movements of $\mathrm{K}^{+}$ions across the inner mitochondrial membrane, such as their influx into the matrix through electrogenic mechanisms $\left(\mathrm{K}^{+}\right.$channels and $\mathrm{K}^{+}$leak) and their extrusion mainly due to $\mathrm{K}^{+} / \mathrm{H}^{+}$exchanger, are fundamentally involved in the control of the matrix volume [35-37].

In particular, the opening of $\mathrm{K}^{+}$channels leads to a $\mathrm{K}^{+}$influx exceeding the $\mathrm{K}^{+}$extrusion, which is compensated by increased $\mathrm{H}^{+}$outward pumping and accumulation of phosphates in the matrix. This causes osmotic influx of water and mitochondrial swelling [37,38]. These effects on mitochondrial volume are considered the most relevant physiological consequences of mito- $\mathrm{K}_{\mathrm{ATP}}$ activation [6]; in agreement with its pharmacodynamic feature of a $\mathrm{K}^{+}$channel activator, diazoxide caused 
mitochondrial swelling, at the same concentration evoking protective effects on H9c2 cells. A similar effect was produced by compound $\mathbf{A}$, which caused mitochondrial swelling, but at a concentration slightly higher (about one order of magnitude) than that exhibiting protective effects on $\mathrm{H} 9 \mathrm{c} 2$ cells.

Mitochondria represent a powerful mechanism for buffering excessive increases of cytosolic $\mathrm{Ca}^{++}$, through an avid accumulation into the matrix, mainly mediated by $\mathrm{Ca}^{++}$- uniporter and facilitated by the large electrochemical gradient [39]. Influx of $\mathrm{K}^{+}$ions causes mitochondrial membrane depolarisation thus reducing $\mathrm{Ca}^{++}$- upload and/or promoting $\mathrm{Ca}^{++}$- release from $\mathrm{Ca}^{++}$- preloaded mitochondria. Diazoxide caused a dose-dependent unloading of $\mathrm{Ca}^{++}$from $\mathrm{Ca}^{++}$charged mitochondria and prevented $\mathrm{Ca}^{++}$upload in $\mathrm{Ca}^{++}$- free mitochondria. The diazoxide-induced $\mathrm{Ca}^{++}$ release from mitochondria was completely abolished by ATP, i.e. by the main endogenous blocker of the $\mathrm{K}_{\mathrm{ATP}}$ channels. These findings are in good agreement with the experimental work of other authors [30].

Moreover, the depolarisation induced by $\mathrm{K}^{+}$channel openers is known to represent a trigger for the transient activation of MPTP [40], which probably prevents a following irreversible and deleterious opening of MPTP at reperfusion [41]. In turn, this transient MPTP opening is the principal pathway for $\mathrm{Ca}^{++}$release from the matrix [42]. Hence, the diazoxide-induced $\mathrm{Ca}^{++}$discharge was also evaluated in the presence of CsA, an inhibitor of MPTP. In these experimental conditions, diazoxide failed to induce $\mathrm{Ca}^{++}$release from mitochondria, in agreement with authoritative data from the literature $[30,40,43]$. The effects of diazoxide on mitochondrial $\mathrm{Ca}^{++}$movements (release and accumulation) were fully mimicked by compound $\mathbf{A}$. As well, the $\mathrm{Ca}^{++}$release induced by compound A was abolished by ATP and CsA. Nevertheless, in this pharmacological feature, compound A showed a level of potency lower than diazoxide. Moreover, the concentrations of compound $\mathbf{A}$ inducing $\mathrm{Ca}^{++}$release from mitochondria were dramatically higher (more than two orders of magnitude) than those required for the protective effects on H9c2 cells. 
In order to evaluate a correlation between the effects on $\mathrm{Ca}^{++}$movements and those on mitochondrial membrane potential, further experiments were made to evaluate the possible depolarising responses and the range of effective concentrations. Both diazoxide and compound $\mathbf{A}$ caused a partial depolarisation of the mitochondrial membrane, and such an effect was antagonised by ATP. As shown in Fig. 10, it is evident that the effects evoked by the two compounds on $\mathrm{Ca}^{++}$ movements and those induced on membrane potential were well correlated $\left(\mathrm{R}^{2}=0.95\right)$. Valinomycin had more intense depolarising effects, which were not affected by ATP (data not shown). Again, as observed in the experiments on the $\mathrm{Ca}^{++}$release, compound $\mathbf{A}$ showed levels of potency lower than the benzothiadiazine diazoxide; and again, as already observed in all the other experimental protocols performed on isolated mitochondria (i.e., the experiments on the $\mathrm{Ca}^{++}$ movements and those on mitochondrial swelling), the concentrations of compound $\mathbf{A}$ inducing depolarising effects were dramatically higher (more than two orders of magnitude) than those required for the protective effects on $\mathrm{H} 9 \mathrm{c} 2$ cells.

However, it should be noted that this discrepancy is not particularly surprising, since such a great difference between the concentrations required to depolarise the mitochondrial membrane potential and cause $\mathrm{Ca}^{++}$release in isolated mitochondria and the concentrations required for a pharmacological activation of mito- $\mathrm{K}_{\mathrm{ATP}}$ channels is a common feature, shared by almost all the mito- $\mathrm{K}_{\mathrm{ATP}}$ openers; indeed, many authors attribute this particular feature to epiphenomenic effects that are independent of mito- $\mathrm{K}_{\mathrm{ATP}}$ channels and that are linked to a non-specific inhibition of the electron transport [6]. Together with the above hypothesis on a non-specific toxicity, recent reports seem to offer other alternative or complementary keys of interpretations. In particular, there is convincing evidence about the involvement of multi-molecular cardioprotective signals (signalosomes) in IPC, which derive from non-mitochondrial compartments (caveolae) and are delivered to mitochondrial membranes, where they trigger complex pathways, involving the activation of mito- $\mathrm{K}_{\mathrm{ATP}}$ channels as a fundamental step [44]. Thus, it cannot be excluded that the interaction between mito- $\mathrm{K}_{\mathrm{ATP}}$-activators and the mito- $\mathrm{K}_{\mathrm{ATP}}$ channel (or the effects deriving from 
such an interaction) might be facilitated and/or strengthened by the presence of other factors, which are present in the whole cells but are lost in the isolated mitochondrial preparations.

Moreover, it should be noted that compound A shows a higher level of lipophylicity $(\log \mathrm{P}=3.34 \pm 0.77)$ than diazoxide $(\log \mathrm{P}=1.07 \pm 0.23)$. Given the intracellular localisation of the pharmacological target, this physico-chemical factor might represent (at least in part) a further "pharmacokinetic factor" affecting the different behaviour of the molecules, when tested in vivo, in isolated hearts, in intact cells or in all the different protocols performed on isolated mitochondria. These aspects will be investigated in future experimental works, more specifically aimed to characterise the pharmacokinetic feature of the new molecule.

In conclusion, this study confirmed the anti-ischemic properties of compound $\mathbf{A}$, indicating that this new derivative is more potent than diazoxide in the in vivo model of heart infarct and, more importantly, its cardiac effects are not accompanied by significant influences on blood pressure and glucose metabolism, which represent serious limits for the use of non-selective agents. On the basis of the actual knowledge on mito- $\mathrm{K}_{\mathrm{ATP}}$ channels and on the pharmacological tools for studying them, the experimental results reasonably suggest that the pharmacodynamic mechanistic basis of cardioprotection resides in the activation of mito- $\mathrm{K}_{\mathrm{ATP}}$ channels. Therefore, compound $\mathbf{A}$ represents in itself an innovative anti-ischemic spiro-benzopyranic molecule and an interesting prototype for the development of improved analogues showing a more favourable therapeutic window.

\section{Acknowledgments}

The authors wish to thank Prof. Maria Rosa Mazzoni (Dipartimento di Psichiatria, Neurobiologia, Farmacologia e Biotecnologie, Università di Pisa) for her kind and helpful assistance for cell cultures.

\section{Conflict of interest}

The authors declare no conflict of interest. 


\section{References}

[1] Murry CE, Jennings RB, Reimer KA. Preconditioning with ischemia: a delay of lethal cell injury in ischemic myocardium. Circulation 1986; 74: 1124-1136.

[2] Halestrap AP, Clarke SJ, Khaliulin I. The role of mitochondria in protection of the heart by preconditioning. Biochim Biophys Acta 2007; 1767: 1007-1031.

[3] Bednarczyk P, Barker GD, Halestrap AP. Determination of the rate of $\mathrm{K}^{+}$movement through potassium channels in isolated rat heart and liver mitochondria. Biochim Biophys Acta 2008; 1777: 540-548.

[4] Garlid KD, Paucek P, Yarov-Yarovoy V, Murray HN, Darbenzio RB, D’Alonzo AJ, Lodge NJ, Smith MA, Grover GJ. Cardioprotective effect of diazoxide and its interaction with mitochondrial ATP-sensitive $\mathrm{K}^{+}$channels. Possible mechanism of cardioprotection. Circ Res 1997; 81: 1072-1082.

[5] Wojtovich AP, Burwell LS, Sherman TA, Nehrke KW, Brookes PS. The C. elegans mitochondrial $\mathrm{K}^{+}$ATP channel: a potential target for preconditioning. Biochem Biophys Res Commun 2008; 376: 625-628.

[6] Garlid KD. Opening mitochondrial K(ATP) in the heart-what happens, and what does not happen. Basic Res Cardiol 2000; 95: 275-279. 
[7] Garlid KD, Dos Santos P, Xie ZJ, Costa AD, Paucek P. Mitochondrial potassium transport: the role of the mitochondrial ATP-sensitive $\mathrm{K}^{+}$channel in cardiac function and cardioprotection. Biochim Biophys Acta 2003; 1606: 1-21.

[8] Halestrap AP. Calcium-dependent opening of a non-specific pore in the mitochondrial inner membrane is inhibited at $\mathrm{pH}$ values below 7. Implications for the protective effect of low $\mathrm{pH}$ against chemical and hypoxic cell damage. Biochem J 1991; 278: 715-719.

[9] Griffiths EJ, Halestrap AP. Mitochondrial non-specific pores remain closed during cardiac ischaemia, but open upon reperfusion. Biochem J 1995; 307: 93-98.

[10] Zhang SZ, Gao Q, Cao CM, Bruce IC, Xia Q. Involvement of the mitochondrial calcium uniporter in cardioprotection by ischemic preconditioning. Life Sci 2006; 78:738-745.

[11] Murata M, Akao M, O’Rourke B, Marbàn E. Mitochondrial ATP-sensitive potassium channels attenuate matrix $\mathrm{Ca}^{2+}$ overload during simulated ischemia and reperfusion. Possible mechanism of cardioprotection. Circ Res 2001; 89: 891-898.

[12] Garlid KD, Paucek P. Mitochondrial potassium transport: the $\mathrm{K}^{+}$cycle. Biochim Biophys Acta 2003; 1606: 23-41.

[13] Halestrap AP. The regulation of the oxidation of fatty acids and other substrates in rat heart mitochondria by changes in matrix volume induced by osmotic strength, valinomycin and $\mathrm{Ca}^{2+}$. Biochem J 1987; 244: 159-164. 
[14] Garlid KD, Paucek P, Yarov-Yarovoy V, Sun X, Schindler PA. The mitochondrial KATP channel as a receptor for potassium channel openers. J Biol Chem 1996; 271 : 8796-8799.

[15] Lebrun P, Antoine MH, Herchuelz A. $\mathrm{K}^{+}$channel openers and insulin release. Life Sci $1992 ; 51: 795-806$.

[16] Atwal KS, Grover GJ, Ahmed SZ, Ferrara FN, Harper TW, Kim KS, Sleph PG, Dzwonczyk S, Russell AD, Moreland S, McCullough JR, Normandin DE. Cardioselective antiischemic ATP-sensitive potassium channel openers. J Med Chem 1993; 36: 3971-3974.

[17] Grover GJ, Atwal KS. Pharmacologic profile of the selective mitochondrial-K(ATP) opener BMS-191095 for treatment of acute myocardial ischemia. Cardiovasc Drug Rev 2002; 20: 121 36.

[18] Breschi MC, Calderone V, Martelli A, Minutolo F, Rapposelli S, Testai L, Tonelli F, Balsamo A. New benzopyran-based openers of the mitochondrial ATP-sensitive potassium channel with potent anti-ischemic properties. J Med Chem 2006; 49: 7600-7602.

[19] Breschi MC, Calderone V, Digiacomo M, Manganaro M, Martelli A, Minutolo F, Rapposelli S, Testai L, Tonelli F, Balsamo A. Spirocyclic benzopyran-based derivatives as new anti-ischemic activators of mitochondrial ATP-sensitive potassium channel. J Med Chem 2008; 51: 6945-6954.

[20] Hanley PJ, Daut J. $K_{\text {ATP }}$ channels and preconditioning: a re-examination of the role of mitochondrial $\mathrm{K}_{\mathrm{ATP}}$ channels and an overview of alternative mechanisms. J Mol Cell Cardiol 2005; 39: 17-50. 
[21] Minners J, Lacerda L, Yellon DM, Opie LH, McLeod CJ, Sack MN. Diazoxide-induced respiratory inhibition - a putative mitochondrial KATP channel independent mechanism of pharmacological preconditioning. Mol Cell Biochem 2007; 294: 11-18.

[22] Rapposelli S, Calderone V, Cirilli R, Digiacomo M, Faggi C, La Torre F, Manganaro M, Martelli A, Testai L. Enantioselectivity in Cardioprotection induced by S-(-)-2,2-dimethyl-N(4'-acetamido-benzyl)-4-spiromorpholone-chromane. J Med Chem 2009; 52: 1477-1480.

[23] Dröse S, Brandt U, Hanley PJ. K ${ }^{+}$-independent Actions of Diazoxide Question the Role of Inner Membrane KATP Channels in Mitochondrial Cytoprotective Signaling. J Biol Chem 2006; 281: 23733-23739.

[24] Kaasik A, Safiulina D, Zharkovsky A, Veksler V. Regulation of mitochondrial matrix volume. Am J Physiol Cell Physiol 2007; 292: C157-C163.

[25] Hwang GS, Oh K-S, Koo H-N, Seo HW, You K-H, Lee BH. Effects of KR-313078, a novel ATP-sensitive potassium channel activator, on hypertrophy of H9c2 cells and on cardiac dysfunction in rats with congestive heart failure. Eur J Pharmacol 2006; 540: 131-138.

[26] Huang Z, Jansson L, Sjöholm Å. Vasoactive drugs enhance pancreatic islet blood flow, augment insulin secretion and improve glucose tolerance in female rats. Clin Sci 2007; 112: 6976.

[27] Hescheler J, Meyer R, Plant S, Krautwurst D, Rosenthal W, Schultz G. Morphological, biochemical, and electrophysiological characterization of a clonal cell (H9c2) line from rat heart. Circ Res 1991; 69: 1476-1486. 
[28] Moon C-H, Kim M-Y, Kim MJ, Kim MH, Lee S, Yi KY, Yoo SE, Lee D-H, Lim H, Kim HS, Lee SH, Baik EJ, Jung Y-S. KR-31378, a novel benzopyran analog, attenuates hypoxiainduced cell death via mitochondrial $\mathrm{K}_{\mathrm{ATP}}$ channel and protein kinase $\mathrm{C}-\varepsilon$ in heart-derived H9c2 cells. Eur J Pharmacol 2004; 506: 27-35.

[29] Chiu PY, Luk KF, Leung HY, Ng KM, Ko KM. Schisandrin B stereoisomers protect against hypoxia/reoxygenation-induced apoptosis and inhibit associated changes in $\mathrm{Ca}^{2+}$ induced mitochondrial permeability transition and mitochondrial membrane potential in H9c2 cardiomyocytes. Life Sci 2008; 82: 1092-1101.

[30] Holmuhamedov EL, Wang L, Terzic A. ATP-sensitive $\mathrm{K}^{+}$channel openers prevent $\mathrm{Ca}^{++}$ overload in rat cardiac mitochondria. J Physiol 1999; 519: 347-360.

[31] Drew B, Leeuwenburgh C. Method for measuring ATP production in isolated mitochondria: ATP production in brain and liver mitochondria of Fischer-344 rats with age and caloric restriction. Am J Physiol Regul Integr Comp Physiol 2003; 285: R1259-1267.

[32] Kopustinskiene DM, Pollesello P, Saris N-EL. Potassium-specific effects of levosimendan on heart mitochondria. Biochem Pharmacol 2004; 68: 807-812.

[33] Labajova A, Vojtiskova A, Krivakova P, Kofranek J, Drahota Z, Houstek J. Evaluation of mitochondrial membrane potential using a computerized device with a tetraphenylphosphonium-selective electrode. Anal Biochem 2006; 353: 37-42. 


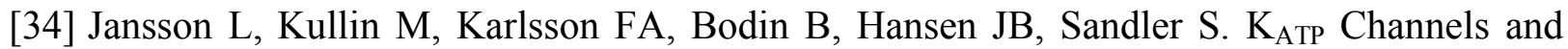
pancreatic islet blood flow in anesthetized rats increased blood flow induced by potassium channel openers. Diabetes 2003; 52: 2043-2048.

[35] Halestrap AP. The regulation of the matrix volume of mammalian mitochondria in vivo and in vitro, and its role in the control of mitochondrial metabolism. Biochim Biophys Acta 1989; 973: 355-382.

[36] Bernardi P. Mitochondrial transport of cations: channels, exchangers, and permeability transition. Physiol Rev 1999; 79: 1127-1155.

[37] Nowikovsky K, Schweyen RJ, Bernardi P. Pathophysiology of mitochondrial volume homeostasis: potassium transport and permeability transition. Biochim Biophys Acta 2009; 1787: $345-350$.

[38] Azzone GF, Azzi A. Volume changes in liver mitochondria. Proc Natl Acad Sci USA 1965; 53: $1084-1089$.

[39] Dedkova EN, Blatter LA. Mitochondrial $\mathrm{Ca}^{++}$and the heart. Cell Calcium 2008; 44: 77-91.

[40] Scorrano L, Petronilli V, Bernardi P. On the voltage dependence of the mitochondrial permeability transition pore. A critical appraisal. J Biol Chem 1997; 272: 12295-12299.

[41] Hausenloy D, Wynne A, Duchen M, Yellon D. Transient mitochondrial permeability transition pore opening mediates preconditioning-induced protection. Circulation 2004; 109 : 1714-1717. 
[42] Gunter TE, Gunter KK, Sheu SS, Gavin CE. Mitochondrial calcium transport: physiological and pathological relevance. Am J Physiol 1994; 267: C313-C339.

[43] Kang SH, Park WS, Kim N, Youm JB, Warda M, Ko JH, Ko EA, Han J . Mitochondrial $\mathrm{Ca}^{++}$- activated $\mathrm{K}^{+}$channels more efficiently reduce mitochondrial $\mathrm{Ca}^{++}$overload in rat ventricular myocytes. Am J Physiol Heart Circ Physiol 2007; 293: H307-H313.

[44] Garlid KD, Costa AD, Quinlan CL, Pierre SV, Dos Santos P. Cardioprotective signaling to mitochondria. J Mol Cell Cardiol 2009; 46: 858-866. 
Figure 1. Chemical structure of compound A. The synthesis of this spiro-morpholone derivative A and analogous molecules is described in Breschi et al., 2006.

Figure 2. Infarct size, expressed as a percentage of the whole area of the left ventricle $\left(\mathrm{Ai} / \mathrm{A}_{\mathrm{LV}} \%\right)$, after different in vivo treatments in a model of coronary occlusion-reperfusion on rat hearts. Bars represent the $\mathrm{Ai} / \mathrm{A}_{\mathrm{LV}} \%$ of the hearts of rats that 2 hours before the experimental procedures received vehicle or respectively an i.p. injection of: diazoxide $40 \mathrm{mg} / \mathrm{Kg}$, compound A (2 mg/Kg, $10 \mathrm{mg} / \mathrm{Kg}, 40 \mathrm{mg} / \mathrm{Kg})$ and 5 -HD $5 \mathrm{mg} / \mathrm{Kg}$ plus compound $\mathbf{A ~} 40 \mathrm{mg} / \mathrm{Kg}$. The effects of IPC are also shown. The asterisks indicate a value significantly different from the vehicle $(*=\mathrm{P}<0.05 ; * *=\mathrm{P}<0.01)$.

Figure 3. Values of systolic blood pressure (expressed in $\mathrm{mmHg}$; A) and heart rate (expressed as beats/min; B), sphygmomanometrically recorded in anaesthetised rats, before and after the i.p. administration (arrow) of vehicle, diazoxide $40 \mathrm{mg} / \mathrm{Kg}$, compound $\mathbf{A} 40 \mathrm{mg} / \mathrm{Kg}$ or cromakalim $1 \mathrm{mg} / \mathrm{Kg}$. The asterisks indicate a value significantly different from the vehicle $(*=$ $\mathrm{P}<0.05 ; * *=\mathrm{P}<0.01 ; * * *=\mathrm{P}<0.001)$.

Figure 4. Changes of glycaemic levels, recorded in anaesthetised rats after the i.p. administration (arrow) of vehicle, diazoxide $40 \mathrm{mg} / \mathrm{Kg}$ or compound A $40 \mathrm{mg} / \mathrm{Kg}$, followed by the i.p. administration of glucose $1 \mathrm{~g} / \mathrm{Kg}$ (at time 0 ). The asterisks indicate a value significantly different from the vehicle $(* * *=\mathrm{P}<0.001)$.

Figure 5. Cell viability normalised as a percentage of the reference values recorded in the nonischemic vehicle-treated cells. The bars represent the $\mathrm{H} 9 \mathrm{c} 2$ viability after the indicated treatments. The symbol indicates a value of viability significantly different from the reference value N.I. $(\# \#=\mathrm{P}<0.01)$. The symbol * means a value of viability significantly different from the vehicle-treated ischemic cells $(*=\mathrm{P}<0.05 ; * *=\mathrm{P}<0.01)$. The symbol \# means statistical differences from the corresponding value obtained in the absence of 5-HD (\# $=\mathrm{P}<0.05$; \#\# $=\mathrm{P}<$ $0.01)$.

Figure 6. Rat heart mitochondrial swelling. A) The histograms report the change in absorbance arbitrary units $(520 \mathrm{~nm})$ in the mitochondrial suspension, at the 15 th minute after the addition of 
vehicle, diazoxide 10 or $100 \mu \mathrm{M}$ and compound A 10 and $100 \mu \mathrm{M}$. B) Time-course curve of the decrease in absorbance at 520nm recorded for 15 minutes after the addition (arrow) of vehicle, diazoxide $100 \mu \mathrm{M}$ and compound A $100 \mu \mathrm{M}$. ANOVA proved that the curves obtained after treatment with diazoxide or compound $\mathbf{A}$ are significantly different from that recorded in vehicle-treated mitochondria.

Figure 7. Concentration-response curves of the $\mathrm{Ca}^{++}$releasing effects evoked by increasing concentrations of diazoxide (A) and compound A (B) in the absence and in the presence of ATP $200 \mu \mathrm{M}$ or CsA $0.2 \mu \mathrm{M}$.

Figure 8. The bars represent the $\mathrm{Ca}^{++}$concentrations measured in the medium, after the addition of $\mathrm{Ca}^{++}$-free mitochondria and their consequent $\mathrm{Ca}^{++}$-uptake, in the presence of the vehicle, diazoxide or compound $\mathbf{A}$. in the absence and in the presence of ATP $200 \mu \mathrm{M}$ or CsA $0.2 \mu \mathrm{M}$. The asterisks indicate a value significantly different from the vehicle $(* * *=\mathrm{P}<0.001)$.

Figure 9. Concentration-response curves for the mitochondrial membrane depolarising effects evoked by increasing concentrations of diazoxide (A) and compound $\mathbf{A}(\mathrm{B})$ in the absence and in the presence of ATP $200 \mu \mathrm{M}$.

Figure 10. The figure shows the reciprocal plotting of the effects produced by each tested concentration of drugs (diazoxide and compound $\mathbf{A}$ ) on mitochondrial membrane potential vs the effects evoked by the same concentrations of the two molecules on $\mathrm{Ca}^{++}$release from $\mathrm{Ca}^{++}$preloaded mitochondria. The linear regression analysis allowed to find a good level of correlation $\left(\mathrm{R}^{2}=0.95\right)$. 


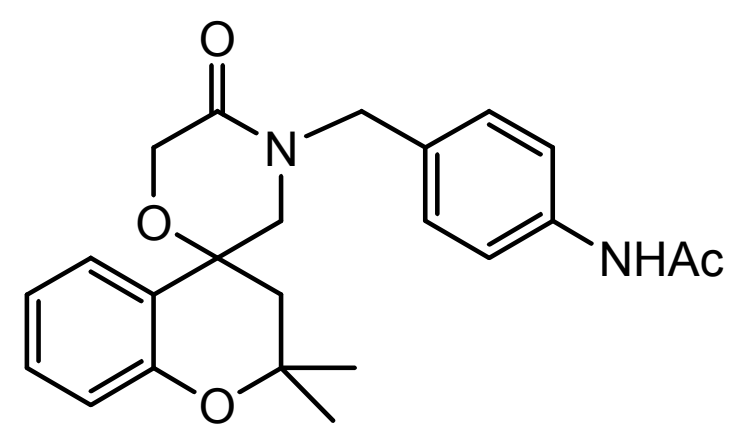

Compound A

Figure 1 


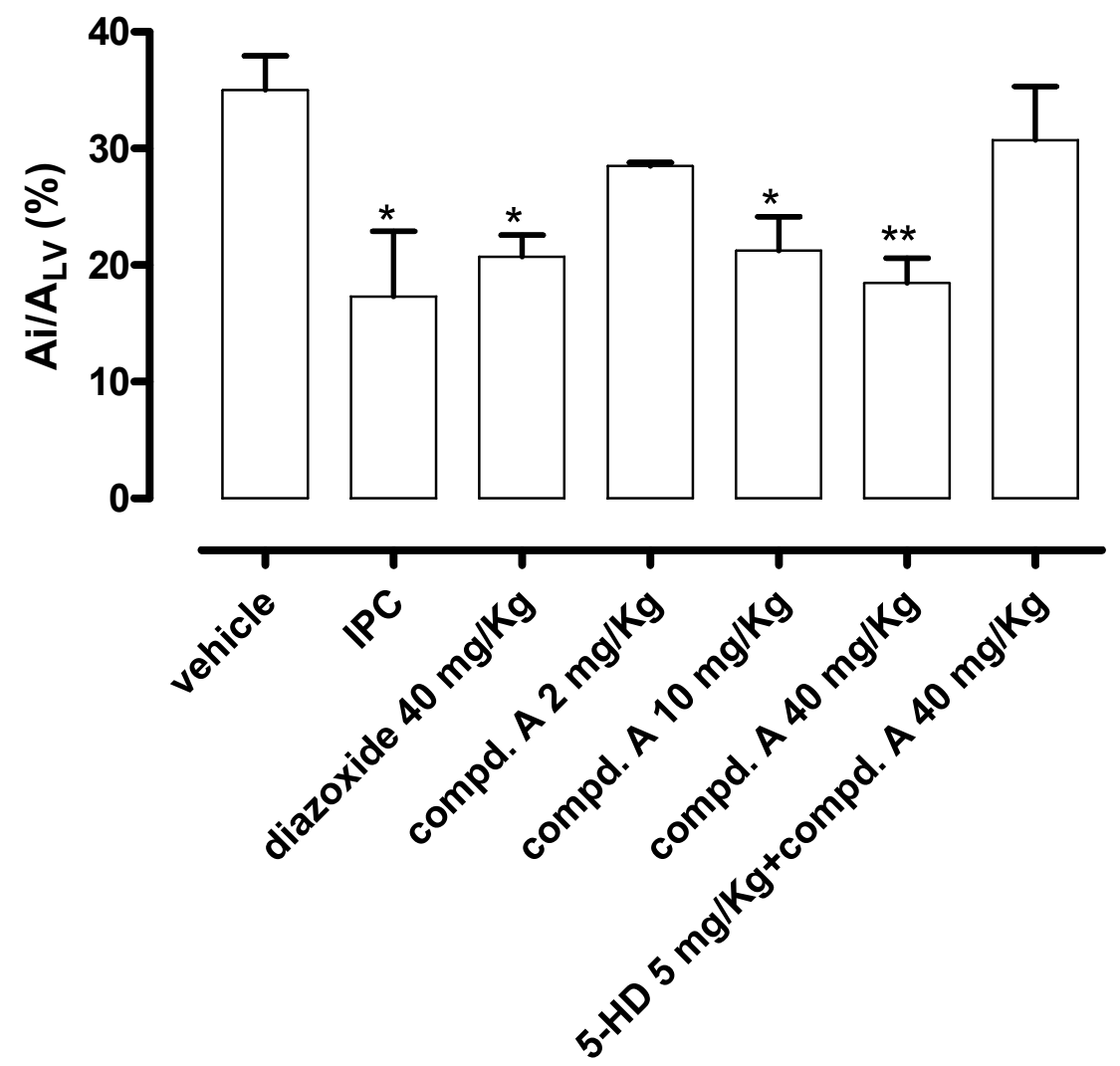

Figure 2 

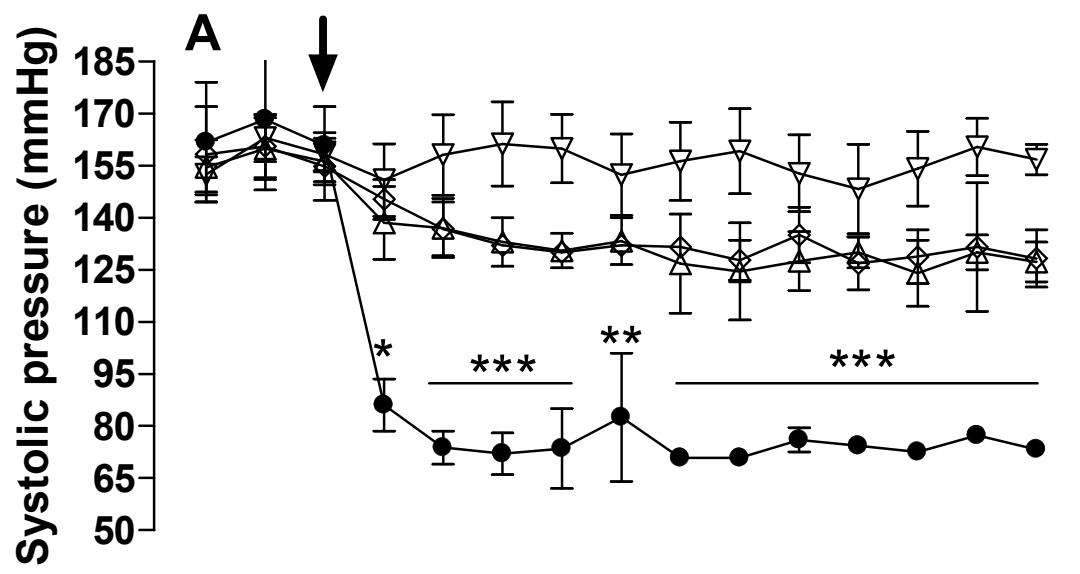

$\nabla$ vehicle

$\triangle$ diazoxide

$\diamond$ compd. A

$\longrightarrow$ cromakalim

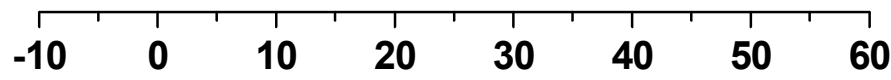

minutes

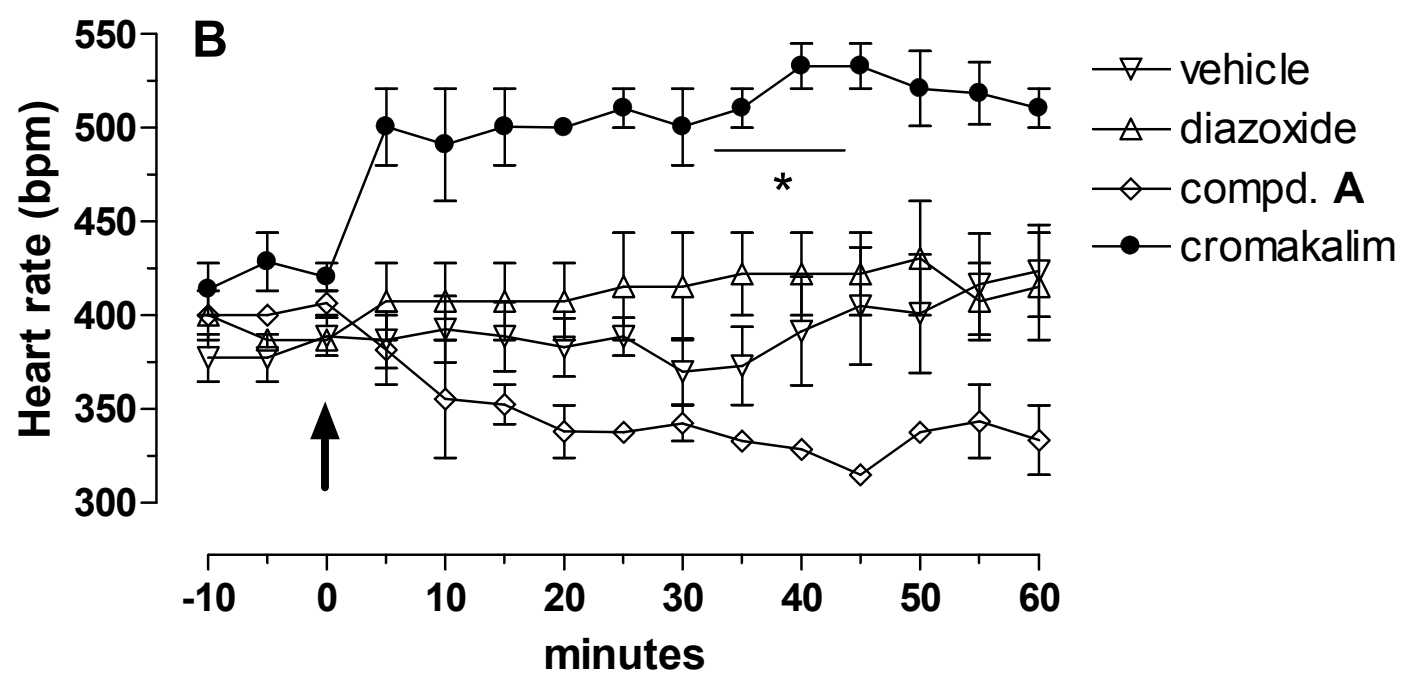

Figure 3 


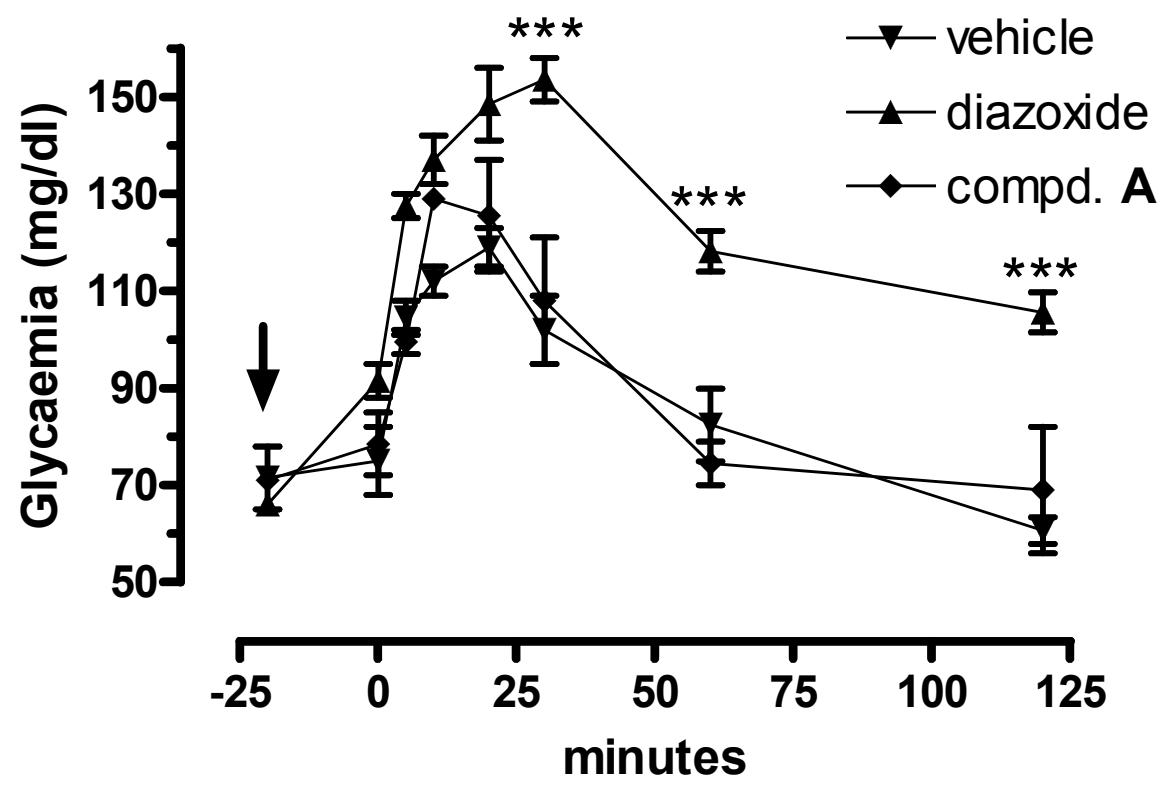

Figure 4 


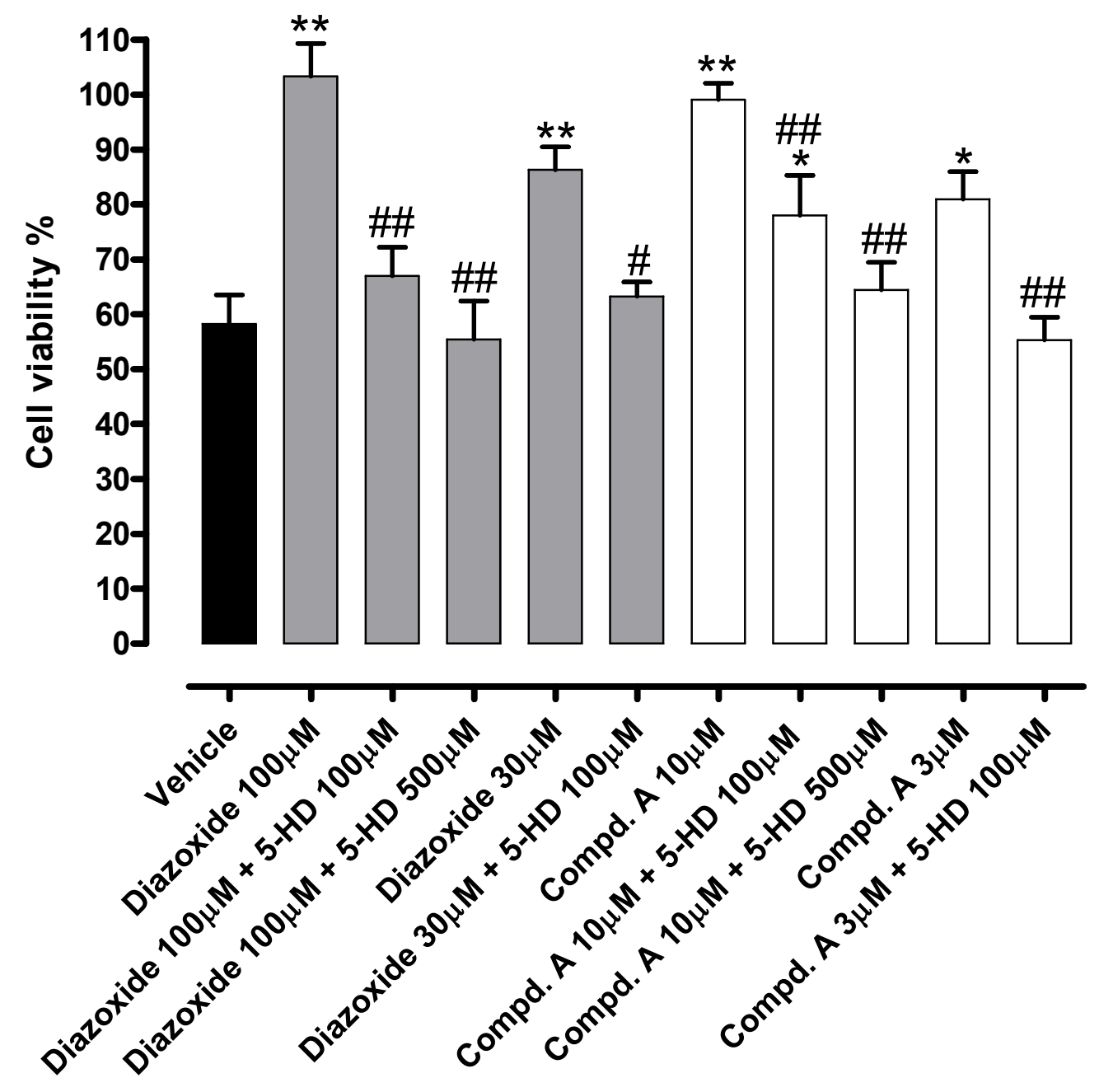

Figure 5 


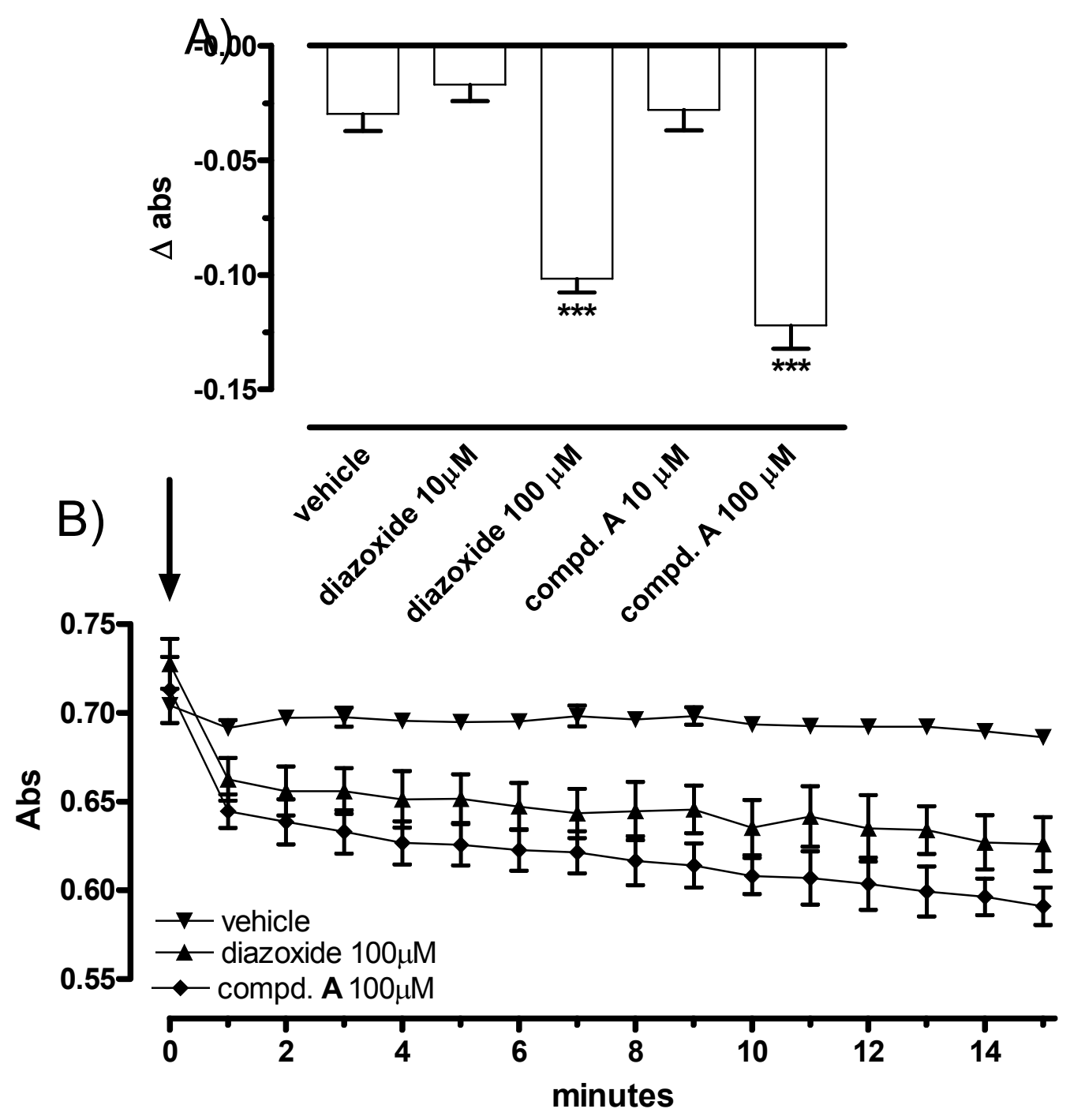

Figure 6 


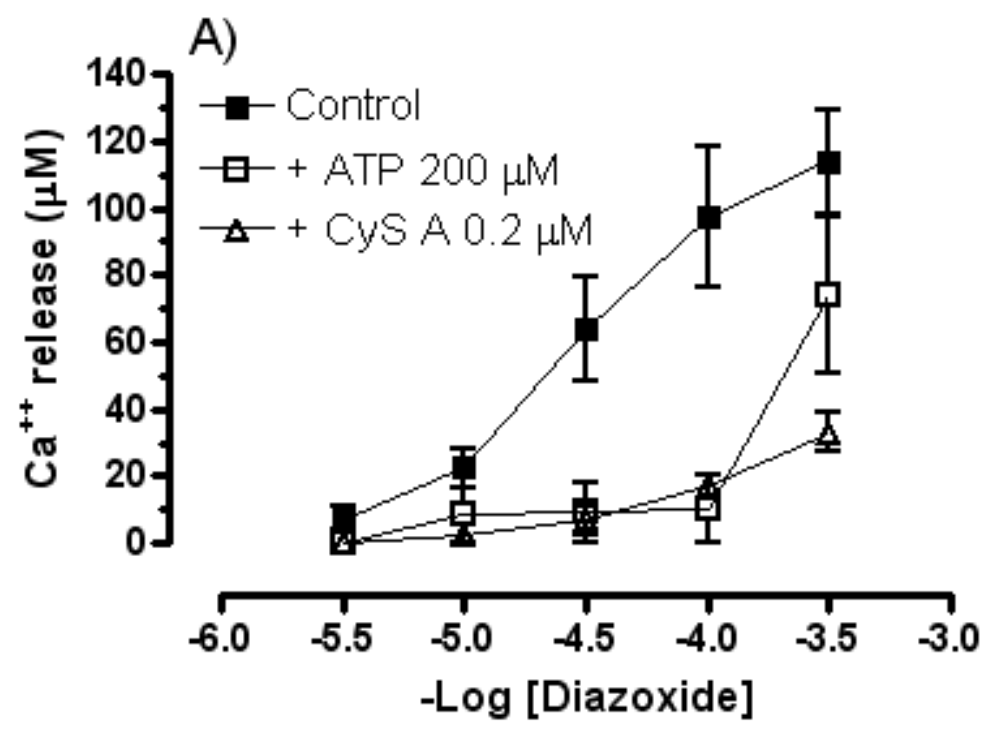

B)

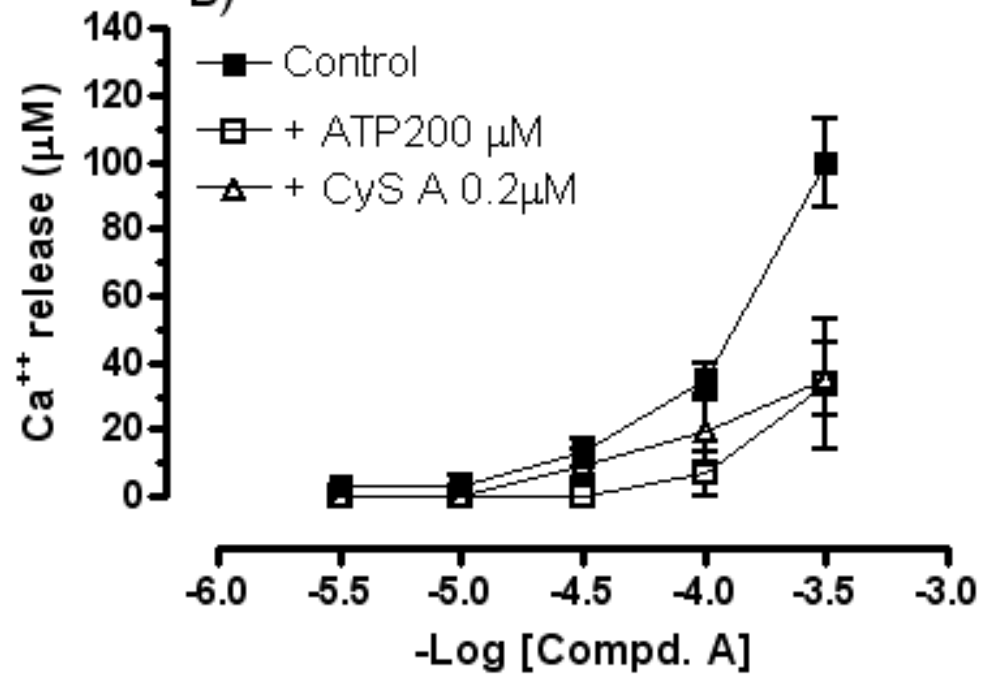

Figure 7 


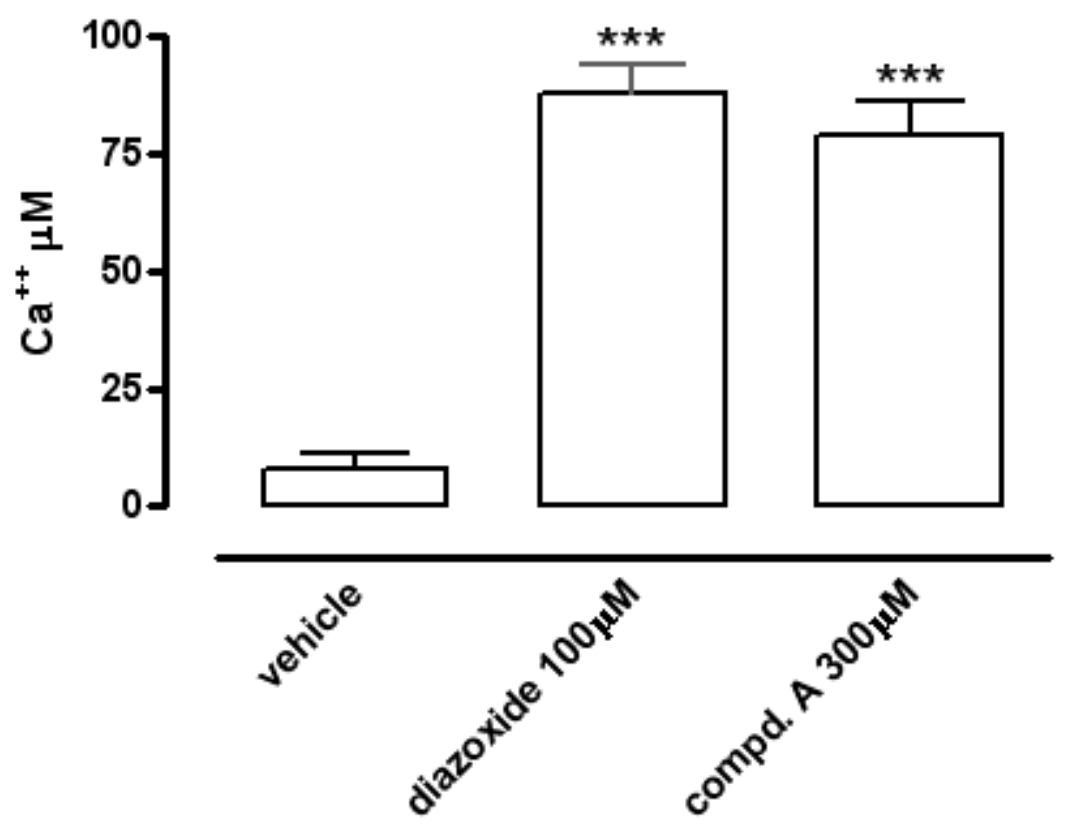

Figure 8 
A)

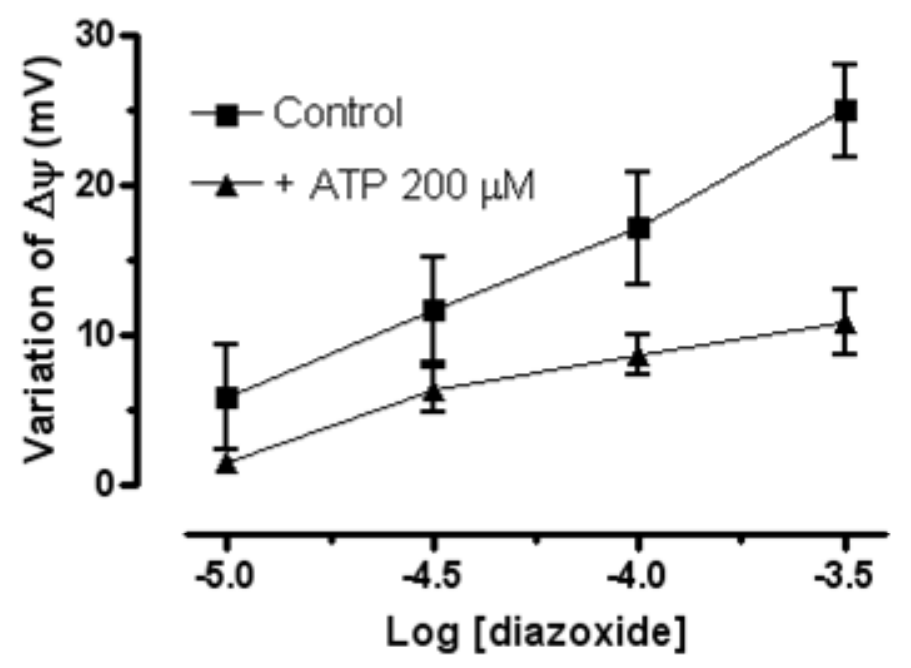

B)

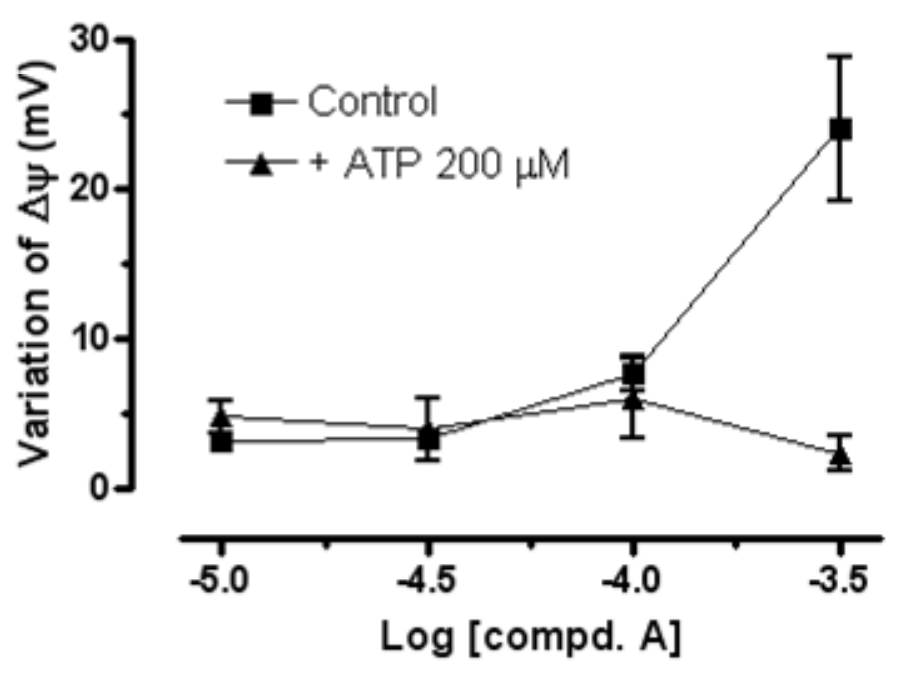

Figure 9 
